\title{
Experimental study of flow dynamics in close-coupled catalyst manifolds
}

Tim Persoons ${ }^{1}(\bowtie)$, Ad Hoefnagels ${ }^{2}$ and Eric Van den Bulck ${ }^{1}$

${ }^{1}$ Katholieke Universiteit Leuven, dept. Mechanical Engineering Celestijnenlaan 300A, B-3001 Leuven, Belgium tel: +32-16-322511, fax: +32-16-322985 email: tim.persoons@mech.kuleuven.be

2 BOSAL International, Advanced Engineering and Testing Lummen, Belgium

\begin{abstract}
Time-resolved flow dynamics in an automotive exhaust manifold with closecoupled catalyst are investigated experimentally on a charged motored engine (CME) flow rig. Flow similarity between $\mathrm{CME}$ and fired engine conditions is discussed analytically. Oscillating hot-wire anemometry (OHW) is used to measure the bidirectional phase-locked velocity. Strong time-resolved mean catalyst velocity fluctuations are observed. These are analysed as Helmholtz resonances, using a one-dimensional gas dynamic model of the manifold. The spatial and temporal occurrence of instantaneous reverse flow in the catalyst is investigated, for varying engine load conditions. Periodic backflow occurs throughout large portions of the catalyst cross-section, and proves to be strongly linked to the observed Helmholtz resonances.
\end{abstract}

Keywords exhaust manifold, close-coupled catalyst, reverse flow, Helmholtz resonance, oscillating hot-wire anemometry

\section{List of notation}

\begin{tabular}{|c|c|}
\hline$A$ & Cross-sectional area $\left[\mathrm{m}^{2}\right]$ \\
\hline$b$ & Cylinder bore $[\mathrm{m}]$ \\
\hline$C_{d}$ & Discharge coefficient [-], for restricted flow across exhaust valve \\
\hline$c$ & Speed of sound $[\mathrm{m} / \mathrm{s}]$ \\
\hline$C_{v}$ & Specific heat capacity at constant volume $[\mathrm{J} / \mathrm{kgK}]$ \\
\hline$d_{e}$ & Diameter of exhaust valve $[\mathrm{m}]$ \\
\hline$e, E$ & Index and number of ensembles [-] \\
\hline$f$ & Frequency $[\mathrm{Hz}]$ \\
\hline$h_{e}$ & Lift height of exhaust valve [m] \\
\hline$i, I$ & Index and number of measurement points [-] \\
\hline$j, J$ & Index and number of crankshaft positions [-] \\
\hline$k$ & Spring constant $[\mathrm{N} / \mathrm{m}]$ \\
\hline$L$ & Length $[\mathrm{m}]$ \\
\hline$L_{f}$ & Theoretical (stoichiometric) air-to-fuel ratio [-] \\
\hline$M$ & Mass flow rate $[\mathrm{kg} / \mathrm{s}]$ \\
\hline$M a$ & Mach number [-] \\
\hline$m$ & Mass $[\mathrm{kg}]$ \\
\hline$N$ & Engine speed [rpm] \\
\hline
\end{tabular}


$n_{e} \quad$ Number of exhaust valves per cylinder [-]

$p \quad$ Pressure [Pa]

$Q \quad$ Volumetric flow rate $\left[\mathrm{m}^{3} / \mathrm{s}\right]$

Re Reynolds number [-], based on runner diameter and mean runner velocity

$R_{f} \quad$ OHW oscillation frequency [-]

$r \quad$ Specific gas constant $[\mathrm{J} / \mathrm{kgK}]$

$S_{f} \quad$ Fuel lower heating value $[\mathrm{J} / \mathrm{kg}]$

$S \quad$ Piston stroke $[\mathrm{m}]$

$T \quad$ Temperature $[\mathrm{K}]$

$t \quad$ Time [s]

U Velocity $[\mathrm{m} / \mathrm{s}]$

$V \quad$ Volume $\left[\mathrm{m}^{3}\right]$

$x, y \quad$ Measurement coordinates [m]

$x_{o} \quad$ OHW oscillation amplitude $[\mathrm{m}]$

\section{Subscripts}

$\begin{array}{ll}0 & \text { Top dead centre } \\ 1 & \text { Peak flow rate during blowdown phase } \\ 2 & \text { Peak flow rate during displacement phase } \\ a & \text { Ambient } \\ b b & \text { Blow-by leakage } \\ c & \text { Combustion } \\ c y l & \text { Cylinder } \\ d & \text { Diffuser } \\ e & \text { Exhaust, or exhaust valve opening } \\ H & \text { Helmholtz resonance } \\ i & \text { Intake, or intake valve closing } \\ m & \text { Mean (area-averaged) } \\ o & \text { OHW (hot-wire oscillator) } \\ p & \text { Hot-wire probe } \\ r & \text { Exhaust runner } \\ r e f & \text { Reference } \\ r e l & \text { Relative (to hot-wire probe) } \\ s & \text { Standard conditions (i.e. } 0{ }^{\circ} \mathrm{C}, 1 \mathrm{~atm} \text { ) }\end{array}$

\section{Greek symbols}

$\alpha \quad$ OHW tolerance factor [-]

$\Delta \theta \quad$ Exhaust valve opening [rad], in crankshaft angle

$\delta Q \quad$ Flow rate deviation from reference [-]

$\phi \quad$ Product of equivalence ratio and combustion efficiency [-]

$\eta \quad$ Flow uniformity measure [-], ratio of mean to maximum velocity

$\kappa \quad$ Ratio of specific heats [-]

$\mu \quad$ Dynamic viscosity [Pa.s]

$\rho \quad$ Density $\left[\mathrm{kg} / \mathrm{m}^{3}\right]$

$\theta \quad$ Crankshaft angle [rad]

$\omega \quad$ Rotational speed $[\mathrm{rad} / \mathrm{s}]$ 


\section{Introduction}

Designing a modern automotive exhaust system requires advanced knowledge on transient fluid dynamics and heat transfer. The exhaust system 'hot end' consists of the exhaust manifold with an integrated close-coupled (CC) catalyst. The manifold typically features three to four exhaust runners that converge in a diffuser volume upstream of the catalyst. Downstream of the catalyst, the gas flows through the exit cone and downpipe into the "cold end' of the exhaust system. The CC catalyst is subjected to pulsating flow, alternating between each of the exhaust runners.

The distance between exhaust ports and CC catalyst is preferably as small as possible, to ensure rapid catalyst warm up, thus reducing cold start emissions. However, this requires exhaust runners with small ratios of length and curvature radius to diameter. On the other hand, obtaining high catalyst flow uniformity is crucial for guaranteeing a low pressure drop (and consequently low fuel consumption), high pollutant conversion rate and long catalyst lifetime. Designing such a manifold while ensuring flow uniformity is a formidable task, requiring state-of-the-art knowledge of fluid dynamics and heat transfer in transient internal flows.

Computational Fluid Dynamics (CFD) simulation of such transient three-dimensional flow is difficult using the Reynolds-averaged Navier-Stokes (RANS) approach. The highly curved runners produce strong secondary flows. Separation and recirculation occurs in exhaust runners and diffuser. The flow is characterised by non-isotropic turbulence and threedimensional boundary layers.

The objective of this research is to provide accurate experimental bidirectional velocity data in the catalyst cross-section, with a high spatial and temporal resolution.

\subsection{Flow in close-coupled catalyst manifolds}

Persoons et al. [1] discuss previous research by the present authors, using an isothermal flow rig for generating cold pulsating flow in two types of exhaust manifolds. The present paper discusses results obtained on a charged motored engine (CME) flow rig that generates cold pulsating flow, which enables the use of hot-wire anemometry (HWA). Unlike the isothermal flow rig however, the CME flow rig features pulsating exhaust flow with blowdown and displacement phases, typical of fired engine conditions. $\$ 2.2$ investigates the flow similarity between fired and CME conditions analytically.

The main contribution of Persoons et al. [1] is the experimental validation of the addition principle. Persoons et al. [2] extends these findings using the CME flow rig. This principle states that the time-averaged velocity distribution in pulsating flow can be predicted by a linear combination of velocity distributions that results from stationary flow through each of the exhaust runners. The principle's validity implies that transient CFD are not required for 
designing a manifold with $\mathrm{CC}$ catalyst with respect to the catalyst flow distribution, but that steady state CFD simulations suffice.

Persoons et al. [1, 2] have validated this addition principle for two types of exhaust manifolds; manifolds B and A, with and without exhaust valve overlap. Pulsating flow is generated using two different pulsators; a rotating valve and a motored cylinder head, both mounted on an isothermal flow rig. The flow generated by the isothermal flow rig is quite different from fired engine conditions, although time-averaged Reynolds and Mach number are in accordance.

The findings concerning the addition principle [1,2] are confirmed to some extent by other sources in literature. Benjamin et al. [3] discuss experimental results on an axisymmetric manifold with catalyst, mounted on an isothermal flow bench with rotating disk pulsator. Traditional phase-locked HWA is used as velocity measurement. No comparison is made between pulsating and stationary flow patterns in terms of the addition principle. Nevertheless, the authors present their results based on the non-dimensional ratio of flow pulsation period to diffuser residence time, similar to the number used in Persoons et al. $[1,2]$ to characterise the flow and correlate the addition principle's validity.

Arias-Garcia et al. [4] compare the superposition of stationary velocity distributions with the pulsating flow distribution on a close-coupled catalyst manifold, which is similar to the one used in the present research. The manifold is mounted on an isothermal and motored engine flow rig. The comparison does not hold for the motored engine flow rig.

Liu et al. [5] use the same isothermal flow rig as Benjamin et al. [3], but with more overlapping inlet velocity pulse shapes. Liu et al. [5] report lower catalyst flow uniformity due to overlapping inlet flow pulses when compared to the results of Benjamin et al. [3] featuring non-overlapping pulses. According to Fig. 7 in Liu et al. [5], as the pulsation frequency increases, non-uniformity decreases, i.e. uniformity increases. This is in agreement with our findings. From the same figure, overlapping inlet flow pulses seem to result in a much lower uniformity when compared to non-overlapping pulses. Our research confirms a slightly lower uniformity in the presence of overlap between exhaust valve openings.

Bressler et al. [6] present results obtained using phase-locked laser-Doppler anemometry (LDA) in a four-runner manifold with $\mathrm{CC}$ catalyst, mounted on an isothermal flow rig. The authors use a non-dimensional ratio to characterise the flow, similar to Benjamin et al. [3] and Persoons et al. [1].

These and other studies using isothermal pulsating flow rigs do not exhibit reverse flow. This is confirmed by phase-locked LDA results by Hwang et al. [7], obtained on an isothermal flow rig.

\subsection{Helmholtz resonances}

Measurements discussed in Persoons et al. [1] revealed Helmholtz resonances in both CC catalyst manifolds under investigation. This phenomenon only occurs with the cylinder head 
and not with the rotating valve as pulsator, most likely because of the different magnitude and frequency content of the excitation exerted by the pulsator to the flow in the manifold. On the CME flow rig, Helmholtz resonances remain present and cause strong catalyst velocity fluctuations. Many sources in literature show similar resonances, although explanations as to their origin vary.

Adam et al. [8] use a one-dimensional gas dynamic model to provide boundary conditions for transient three-dimensional CFD simulation of the flow in a CC catalyst manifold. The simulation results give clear evidence of Helmholtz resonances in fired engine conditions.

Liu et al. [9] combine a one- and three-dimensional model in the same way as Adam et al. [8]. The authors present simulations for a fired and motored engine with atmospheric intake conditions. For fired conditions, simulated runner velocity indicates the presence of strong Helmholtz resonances.

Park et al. [10] present experimental data obtained using phase-locked LDA on a fired engine. The time-resolved runner velocity shows typical fluctuations at frequencies consistent with a Helmholtz resonance.

Benjamin et al. [11] present experimental data obtained using phase-locked LDA on a fired engine. The authors compare their velocity measurements to a numerical approach similar to Liu et al. [9] and Adam et al. [8]. The paper demonstrates fluctuations in runner and catalyst velocity, both in the experimental and numerical data.

Regardless of differences in exhaust system geometries, the findings of the present research are in agreement with those of Adam et al. [8], Liu et al. [9], Park et al. [10] and Benjamin et al. [11]. §3.2 discusses and explains the Helmholtz resonances observed in the current study.

\subsection{Reverse flow}

The results by the aforementioned authors $[8,9,10,11]$ indicate strong flow reversal immediately following blowdown. The occurrence of reverse flow throughout the engine operating range may be surprising, considering the pressure drop generated by the $\mathrm{CC}$ catalyst. The current research uses an exhaust manifold with free discharge into atmosphere, i.e. without exit cone and 'cold end' tailpipe. The influence of the absence of the exit cone and tailpipe backpressure on the velocity distribution is not investigated. However, the exit cone cannot be solely responsible for the occurrence of flow reversal. Liu et al. [9], Park et al. [10], Benjamin et al. [11] and Kim et al. [12] present experimental or numerical results showing reverse flow in a CC catalyst monolith in fired conditions, including an outlet section. Reverse flow consistently occurs after blowdown. In the absence of blowdown such as on an isothermal flow rig, reverse flow is not likely to occur, which is confirmed by Hwang et al. [7]. §3.3 discusses similar reverse flow observed in the current research. 


\subsection{Measurement techniques}

Obtaining high-quality experimental data that captures instantaneous reverse flow is not straightforward. Optical measurement techniques such as LDA are able to measure bidirectional velocity. However, these techniques require high quality optical access and adequate seeding in the entire measurement region. LDA-based research in CC catalyst systems is often plagued with areas of low seeding concentration. This makes it very difficult to obtain a sufficiently high data rate for measuring time-resolved catalyst velocity distributions. Most studies using LDA only measure velocity in a single point or along a single straight line in the manifold.

Hot-wire anemometry (HWA) requires neither optical access nor seeding, although obviously, physical access for the hot-wire probe is required. HWA features a number of advantages including high bandwidth, continuous output signal and good spatial resolution. The main disadvantage of HWA is its inability to discern flow reversal.

A reference work on thermal anemometry by Bruun [13] contains an overview of techniques for measuring in reversing flows using HWA. On one hand, thermal wake probes relate the time-of-flight of a small heated amount of fluid to the local velocity. This approach is characterised by low bandwidth and is better suited for near-wall measurements. On the other hand, flying HWA is used for measuring in free-stream reversing flows. If the hot-wire probe moves at a sufficiently high velocity counter to the normal flow velocity, the relative velocity seen by the probe can remain positive, even though the absolute velocity is negative. Traditional flying HWA devices such as the system described by Thompson and Whitelaw [14] are quite large and cumbersome, making it impossible to use in confined geometries such as exhaust systems.

Persoons et al. [15] describe the calibration of an oscillating hot-wire anemometer (OHW) device, which is used in the current research. The device is calibrated using phase-locked LDA as reference velocity measurement. It is compact enough to be used to measure velocity distributions in the $\mathrm{CC}$ catalyst. The $\mathrm{OHW}$ features a maximum measurable negative velocity of $-1.0 \mathrm{~m} / \mathrm{s}$, which is sufficient for the current research. This value is comparable to other flying and oscillating HWA devices.

\section{Experimental set up}

\section{1 $\mathrm{CME}$}

The charged motored engine (CME) flow rig consists of a four-cylinder double overhead camshaft gasoline engine with four valves per cylinder, mounted on a dynamic engine test stand with an electric DC dyno. The engine is motored at a constant speed. To enable charging the engine with compressed air, the original intake system has been replaced by a reinforced intake system with identical manifold volume and runner dimensions. The engine 
is run without combustion and fuel injection, to obtain cold clean pulsating flow in the exhaust system. The residual cylinder pressure (prior to exhaust valve opening) is adjusted by means of the intake system pressure. By setting the appropriate residual cylinder pressure, the flow in the exhaust system corresponds to various engine load conditions.

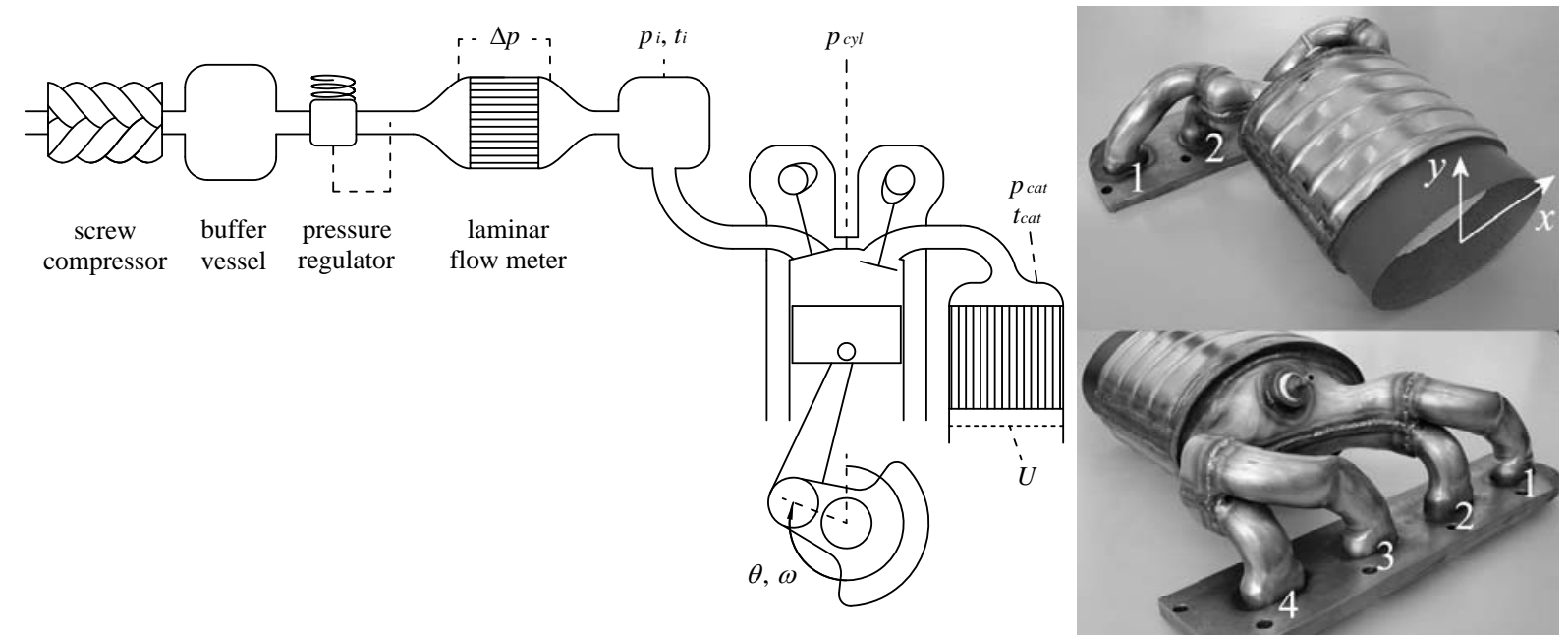

\section{Figure 1. CME flow rig (left) and exhaust manifold (right)}

The original exhaust valve timing is unchanged (Table 1). However, the intake camshaft is retarded by $30{ }^{\circ} \mathrm{ca}$ to avoid unphysical blow-through from high-pressure intake to lowpressure exhaust system during intake/exhaust valve overlap.

Table 1. Manifold specifications

\begin{aligned} \hline Engine (valve timing) & $1.21 \mathrm{I}-4$, DOHC 16 valves $(+17|+250|-220 \mid+13)^{1} \\$\hline Runners & $\varnothing 28 \mathrm{~mm}$, lengths: (\#1) $160 \mathrm{~mm},(\# 2) 80 \mathrm{~mm},(\# 3) 160 \mathrm{~mm},(\# 4) 80 \mathrm{~mm} \\$\hline Diffuser & volume $V_{d}=390.2 \mathrm{~cm}^{3} \\$\hline Catalyst & Ceramic $600 \mathrm{cpsi} / 3 \mathrm{mil}$, square channels, washcoated. Oval cross-section $(\varnothing 151 \mathrm{x} \\ & 101 \mathrm{~mm})$, length $137 \mathrm{~mm}\end{aligned}$

The engine is mounted without vibration dampers onto the rigid test stand frame. An automated positioning system is fixed onto the lab floor adjacent to the test stand, taking care to avoid any relative motion between engine exhaust system and velocity probe. The hot-wire oscillator (OHW) is mounted on the positioning system and traversed automatically through the measurement grid.

Figure 1 (left) schematically depicts the CME flow rig. The compressed air is produced using a screw compressor, which delivers a maximum flow rate of $320 \mathrm{~kg} / \mathrm{h}$ at $8 \mathrm{~atm}$. A pressure regulator maintains a constant pressure in the engine intake system, varying between $1.00 \mathrm{~atm}$ to $2.25 \mathrm{~atm}$ in the current study. The screw compressor's maximum flow rate has limited the engine speed in the current measurements to $3000 \mathrm{rpm}$.

\footnotetext{
${ }^{1}$ Valve timing is indicated as IVO | IVC | EVO | EVC. Original intake valve timing has been retarded by 30 ${ }^{\circ}$ crankshaft angle. Exhaust valve timing is unchanged.
} 
Intake system flow rate is measured using a laminar flow meter. Partly because of the altered intake timing, intake flow rate is highly pulsating with periods of backflow. Although the laminar flow meter is designed for such flows, the intake system flow rate is further verified using a piezo-electric cylinder pressure sensor. The pressure rise during the compression stroke is used to determine the mass flow rate. The intake flow rate reading is accurate to within $5 \%$ to $10 \%$, and serves as reference flow rate for the flow rate obtained by integration of the catalyst velocity distribution.

\subsection{Flow similarity}

The CME flow rig aims to generate pulsating flow in the exhaust manifold that closely resembles fired engine conditions. However, the exhaust flow is cold thus enabling the use of conventional hot-wire anemometry (HWA).

The cold pulsating flow generated by the CME flow rig in the exhaust system is quite different from the isothermal flow rig [1]. By controlling the intake system pressure, the residual cylinder pressure at exhaust valve opening can be adjusted. This results in a twostage exhaust stroke with blowdown and displacement phases, typical of fired engine conditions.

To compare fired engine conditions with $\mathrm{CME}$ and isothermal flow rig conditions, simulations are performed using a filling-and-emptying engine model written in Matlab ${ }^{\mathrm{TM}}$ (e.g. Watson and Janota [17]). The engine model consists of zero-dimensional volumes (intake and exhaust manifold, cylinders) combined with one-dimensional pipes for the intake runners. The model uses the appropriate descriptions for compressible restricted flow over intake and exhaust valves. The combustion process is modelled using a Wiebe law for heat release. Heat loss to the combustion chamber walls is incorporated. Blow-by leakage is taken into account based on experiments on the CME flow rig.

For an engine speed of $1800 \mathrm{rpm}$ and an exhaust flow rate of $100 \mathrm{~m}^{3} / \mathrm{h}$, Fig. 2 shows the timeresolved non-dimensional velocity in runner \#1 of manifold $\mathrm{B}$. The solid and dashed lines represent simulations performed for $\mathrm{CME}$ and isothermal flow rig. The markers indicate the runner velocity measured on the CME flow rig. The non-dimensional exhaust valve lift is plotted in grey.

The isothermal flow rig produces a single-stage exhaust pulse, resulting in four quasisinusoidal pulses per engine cycle. The CME flow rig produces a pulsating flow that strongly resembles fired engine conditions. The two-stage exhaust pulses are more distorted, resulting in an exhaust flow rate with higher frequency content. The difference between measured and simulated velocity is due to Helmholtz resonances that are most pronounced during the displacement phase. The filling-and-emptying engine model does not incorporate a sufficiently accurate exhaust system model to capture this effect. 


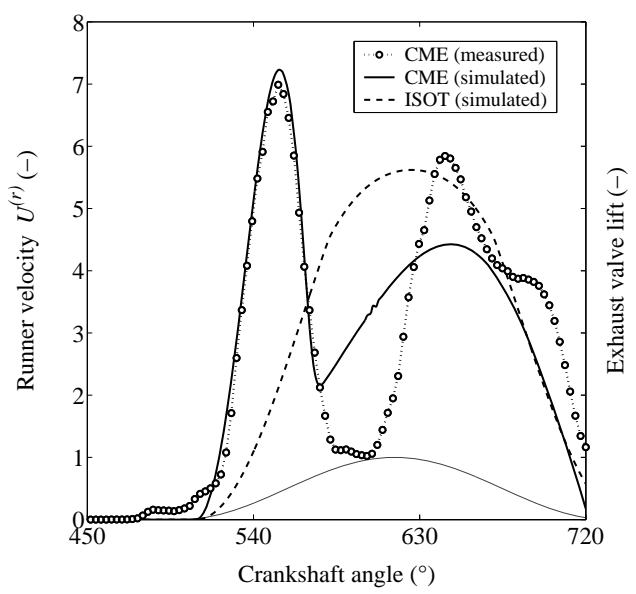

Figure 2. Comparison of exhaust runner velocity for CME and isothermal flow rig [1]

The analytical derivation in the Appendix results in the following expressions for the peak mass flow rate during blowdown $M_{1}[\mathrm{~kg} / \mathrm{s}]$ and displacement phase $M_{2}[\mathrm{~kg} / \mathrm{s}]$ :

$$
\begin{gathered}
M_{1}=\rho_{i} V_{i} \omega\left(2 C_{d} \frac{n_{e} \pi^{3} d_{e} h_{e}}{\Delta \theta^{2}} \frac{\sqrt{r T_{i}}}{\omega V_{i}}\right)^{\frac{1}{3}}\left(\frac{V_{i}}{V_{e}}\right)^{\frac{\kappa-7}{6}} \underbrace{\left(1+\frac{\Delta T_{c}}{T_{i}}\left(\frac{V_{0}}{V_{i}}\right)^{\kappa-1}\right)^{\frac{\kappa-8}{6 \kappa}}}_{i i} \\
\cdot \underbrace{\left(\frac{p_{i}}{p_{a}}\right)^{\frac{-4}{3 \kappa}}}_{i}(\underbrace{\left(\frac{p_{i}}{p_{a}}\right)^{\frac{1}{\kappa}}}_{i}\left(\frac{V_{i}}{V_{e}}\right) \underbrace{\left(1+\frac{\Delta T_{c}}{T_{i}}\left(\frac{V_{0}}{V_{i}}\right)^{\kappa-1}\right)^{\frac{1}{\kappa}}}_{i i}-1) \\
M_{2}=\rho_{i}\left(\frac{\pi b^{2}}{4} s\right) \frac{\omega}{2} \underbrace{\left(\frac{p_{i}}{p_{a}}\right)^{\frac{-1}{\kappa}}}_{i} \underbrace{\left(1+\frac{\left.\Delta T_{c}\left(\frac{V_{0}}{T_{i}}\right)^{\kappa-1}\right)^{\frac{-1}{\kappa}}}{V_{i}}\right)^{(1)}}_{\text {ii }}
\end{gathered}
$$

In Eqs. (1) and (2), term $i$ represents the influence of the intake system pressure. It varies from roughly 0.25 to 1 for a fired engine and from 1 to 2.5 for the CME experiments. Term $i$ represents the influence of the combustion process, where $\Delta T_{c}$ represents the temperature rise due to combustion. For the CME flow rig, there is no combustion, reducing term ii to 1 .

As the engine load increases, intake system pressure (or equivalently term $i$ ) increases. Eqs. (1) and (2) show that the peak mass flow rate increases during blowdown and decreases during displacement. For the CME flow rig, in the absence of combustion, the intake system pressure should result in peak flow rates comparable to fired engine conditions. An appropriate change in term $i$ should compensate for the change in term ii. Figure 3 shows the evolution of $M_{1}$ and $M_{2}$ according to Eqs. (1) and (2) versus intake pressure, for fired and CME conditions. $M_{1}$ and $M_{2}$ are non-dimensionalised using a reference mass flow rate $M_{r e f}$ $[\mathrm{kg} / \mathrm{s}]$, assuming a volumetric efficiency of unity: 


$$
M_{r e f}=\rho_{i}\left(\frac{\pi b^{2}}{4} s\right) \frac{\omega}{4 \pi} \frac{720}{180}
$$

$M_{\text {ref }}$ corresponds to a hypothetical exhaust stroke of $180^{\circ} \mathrm{ca}$ (hence the factor $720 / 180$ ), where the total gas mass is exhausted at a constant mass flow rate $M_{\text {ref. }}$. For the CME flow rig at low intake pressure, $M_{1}$ is negative because of the early opening of the exhaust valve ( $V_{i}$ is smaller than $V_{e}$ ). This is not the case for the fired engine with original intake valve timing. For the CME flow rig, the intake camshaft timing is retarded by $30^{\circ} \mathrm{ca}$, to avoid intake/exhaust valve overlap. Valve overlap would yield a high flow rate through the combustion chamber from the high pressure in the intake system to the exhaust system. This does not occur in the fired engine and as such, the intake timing is adjusted on the CME flow rig.

The high ratio of blowdown to displacement peak flow rate $M_{1} / M_{2}$ can only be achieved on the CME flow rig by increasing intake pressure $p_{i} / p_{a}$ to roughly 5 . In that case, without altering the compression ratio, the maximum cylinder pressure is too high. Furthermore, because of in-cylinder heat loss, blow-by leakage and the fact that $V_{i} / V_{e}<1$, exhaust flow temperature drops below $0{ }^{\circ} \mathrm{C}$ roughly when $p_{i} / p_{a}>2.5$. In that case, water vapour condenses from the air and freezes inside the exhaust manifold. The ice deposits gradually block the small catalyst channels. Possibilities for extending the operating range include using an air heater in the intake system or changing the intake camshaft entirely. None of these options is pursued in this research.

With respect to flow similarity, not only the mass flow rate-based non-dimensional groups $M_{1} / M_{r e f}, M_{2} / M_{r e f}$ and $M_{1} / M_{2}$ should be taken into account. The Reynolds and Mach number based on mean runner velocity and diameter are expressed as:

$$
R e=\frac{U_{r} d_{r}}{\mu / \rho} ; \quad M a=\frac{U_{r}}{\sqrt{\kappa r T}}
$$

where $U_{r}=$ runner mean velocity $[\mathrm{m} / \mathrm{s}]=\dot{m} /\left(\rho \pi d_{r}^{2} / 4\right), d_{r}=$ runner hydraulic diameter [m], $\mu=$ dynamic viscosity [Pa.s]. Assuming the exhaust manifold pressure equals atmospheric pressure, the density $\rho$ can be written as:

$$
\rho=\rho_{i}\left(\frac{p_{i}}{p_{a}}\right)^{\frac{-1}{\kappa}}\left(1+\frac{\Delta T_{c}}{T_{i}}\left(\frac{V_{0}}{V_{i}}\right)^{\kappa-1}\right)^{\frac{-1}{\kappa}}
$$



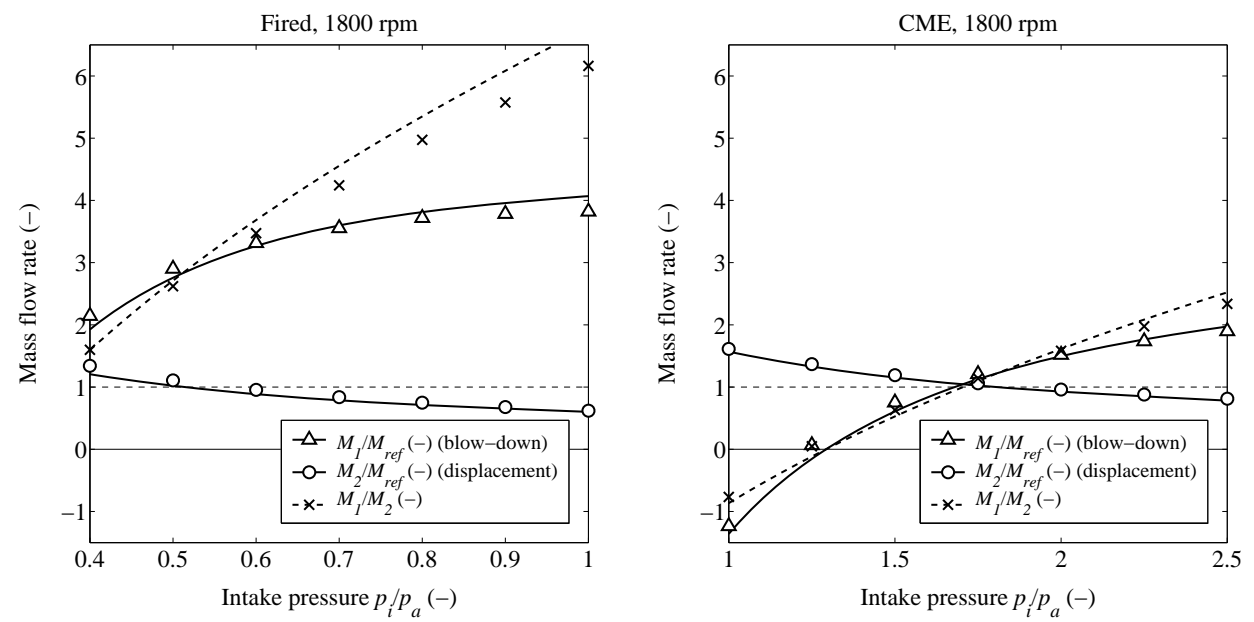

Figure 3. Mass flow rate ${ }^{2}$ versus engine load $p_{i} / p_{a}$, for (left) fired engine and (right) CME
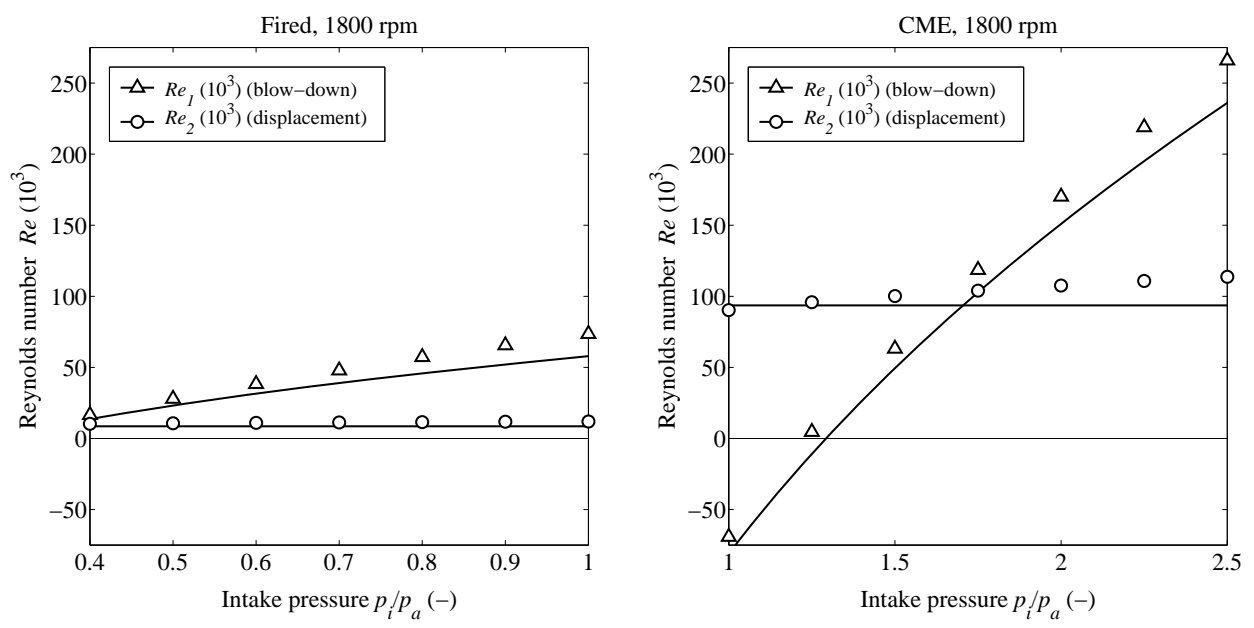

Figure 4. Reynolds number ${ }^{2}$ versus engine load $p_{i} / p_{a}$, for (left) fired engine and (right) CME
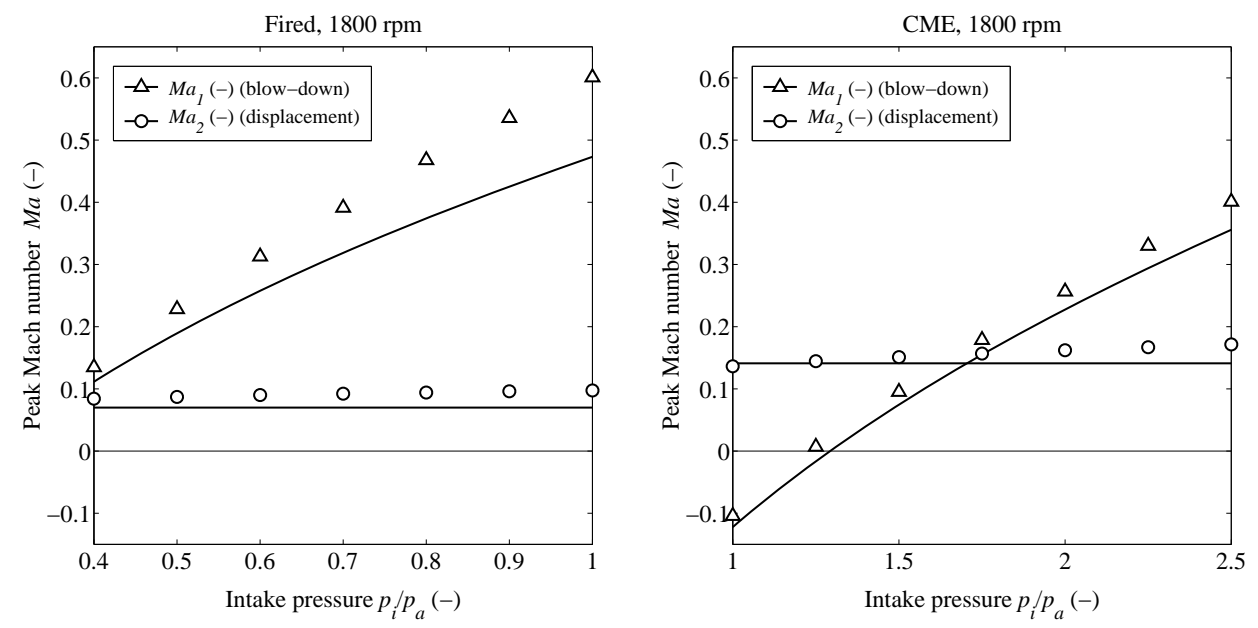

Figure 5. Mach number ${ }^{2}$ versus engine load $p_{i} / p_{a}$, for (left) fired engine and (right) CME

\footnotetext{
${ }^{2}$ Solid lines result from the analytical derivation; the markers result from the filling-and-emptying engine model.
} 
Due to the strong temperature dependence of the dynamic viscosity, the Reynolds number differs significantly between fired and CME conditions. Figure 4 indicates that the ratio of $R e$ from CME to fired conditions approximates 2.5 during blowdown and 10 during displacement phase. Figure 5 shows that the Mach number is comparable in CME and fired conditions.

\subsection{OHW}

To measure bidirectional phase-locked velocity in the exhaust manifold, a hot-wire oscillator (OHW) is used in the current research, which is described in detail in Persoons et al. [15]. The system uses a slider-crank mechanism to oscillate a hot-wire probe with an amplitude $x_{o}=5.5$ $\mathrm{mm}$, at a frequency $f_{o}$ from 30 to $40 \mathrm{~Hz}$. A speed-controlled DC motor maintains the oscillation frequency $f_{o}$ in proportion to the engine speed $N$ [rpm]. The non-dimensional oscillation frequency $R_{f}$ is defined as $R_{f}=f_{o} /(N / 120)=\omega_{o} /(\omega / 2)$.

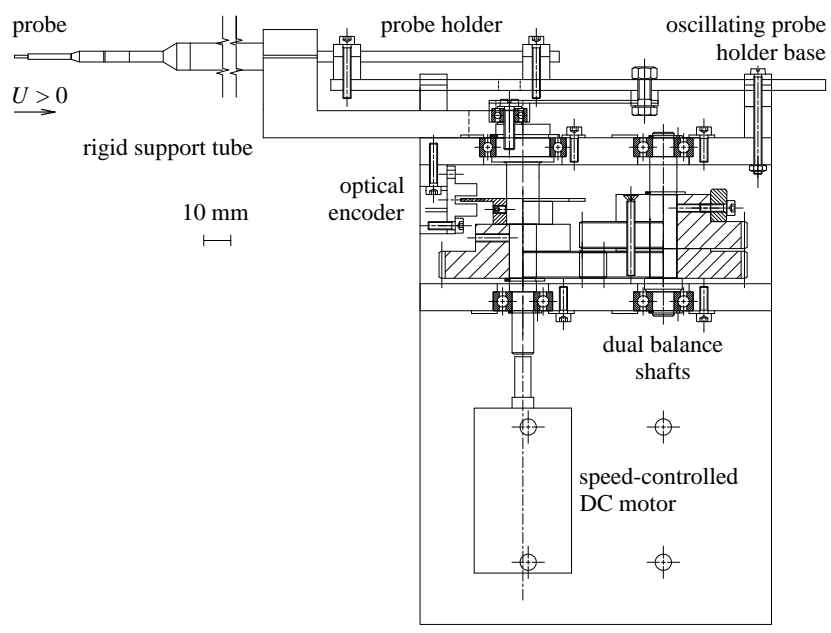

Figure 6. Hot-wire oscillator (OHW) used to measure bidirectional velocity

The normal positive direction of flow is as indicated in Fig. 6. The measured OHW velocity $U^{\prime}$ is defined as $U^{\prime}=U_{r e l}+U_{p}$, where $U_{r e l}=$ relative velocity as seen by the probe $[\mathrm{m} / \mathrm{s}]$ and $U_{p}=$ probe velocity $[\mathrm{m} / \mathrm{s}]$. The relative velocity $U_{r e l}$ is determined from the anemometer bridge output voltage, and the probe velocity $U_{p}$ is determined from the oscillator drive shaft position.

In reverse flow when $U \leq 0$, the OHW provides a valid measurement as long as the relative velocity $U_{r e l} \geq 0$, or the probe velocity $U_{p} \leq U \leq 0$. As the probe oscillates, measurements are accepted in a window around the maximal negative probe velocity $U_{p}$, or symbolically when $U_{p} \leq-2 \pi f_{o} x_{o} \alpha=-\omega_{o} x_{o} \alpha$. Approximating the probe motion as purely sinusoidal, this corresponds to $-\arccos \alpha \leq \omega_{o} t+2 \pi n \leq \arccos \alpha(n \in \square)$. The tolerance factor $\alpha$ is chosen arbitrarily as $\alpha=\cos (\pi / 4) \cong 0.71$. 
When the non-dimensional OHW frequency $R_{f}$ is a whole number, the OHW moves in synchronisation with the engine's crankshaft. In that case, the OHW measurements are taken in the same crankshaft angle intervals in consecutive engine cycles. In order to cover the entire crankshaft position range from 0 to $720^{\circ} \mathrm{ca}$, the $\mathrm{OHW}$ motion slightly lags or leads the engine rotation. $R_{f}$ is arbitrarily chosen as $R_{f}=n \pm 1 / 4(n \in \square)$. The value $1 / 4$ corresponds to the choice of $\alpha=\cos (\pi / 4)$.

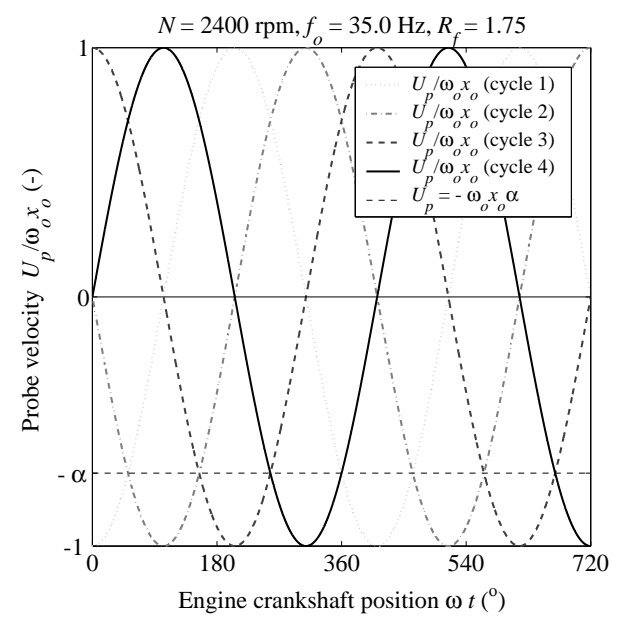

Figure 7. OHW probe velocity, phase-locked with engine crankshaft position

Figure 7 shows the OHW probe velocity versus crankshaft position for a particular engine speed. The oscillator frequency is maximised below $40 \mathrm{~Hz}$, resulting in $f_{o}=35 \mathrm{~Hz}$ for $N=$ $2400 \mathrm{rpm}$, or $R_{f}=2-1 / 4=1.75$. In this case, it takes four engine cycles to obtain measurements for the entire range of crankshaft position from 0 to $720{ }^{\circ} \mathrm{ca}$. Decreasing the value $1 / 4$ to $1 / 8$ increases the mean probe velocity magnitude during OHW measurements, thus increasing resolution in the negative velocity range. However, instead of four, eight engine cycles would be required to complete measurements for one engine cycle. Obtaining valid measurements for one complete engine cycle (i.e. one ensemble) thus takes four engine cycles. Therefore, several hundred cycles are required to ensure sufficient accuracy after ensemble-averaging the velocity data.

A Dantec StreamLine ${ }^{\mathrm{TM}}$ HWA system with Dantec type 90C10 constant temperature anemometer bridge modules has been used for the current research. A Dantec 55P11 probe with extended prongs is used, as described in Persoons et al. [15]. Calibration of the anemometer bridge output voltage to a reference velocity is performed using a Dantec type 90H02 automated free jet calibrator.

The following non-dimensional correlation is used to convert the OHW velocity reading $U^{\prime}$ to the actual velocity $U$. This correlation is obtained during calibration in steady flow, with negative velocity ranging from $U=-1.5$ to $0 \mathrm{~m} / \mathrm{s}$, and positive velocity ranging from 0 to 10 $\mathrm{m} / \mathrm{s}[15]$. 


$$
u^{\prime}= \begin{cases}u+a\left(\sqrt{(u+1)^{2}+b^{2}}-u-\sqrt{1+b^{2}}\right) & (u<0) \\ u & (u \geq 0)\end{cases}
$$

where $u^{\prime}=U^{\prime} / \omega_{o} x_{o}, u=U / \omega_{o} x_{o}, a$ and $b$ are non-dimensional parameters. $a$ determines the slope $(=1-2 a)$ of the function as $u \rightarrow-\infty$ and $b>0$ yields a smooth transition around $u=U / \omega_{o} x_{o}=-1$. In Persoons et al. [15], the values are determined as $a=0.736$ and $b=0.5$, with a coefficient of determination $R^{2}=0.952$.

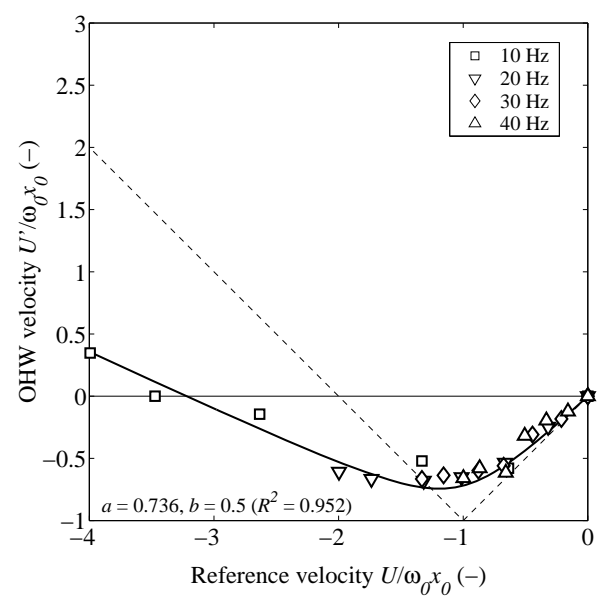

Figure 8. Non-dimensional OHW calibration chart at varying oscillation frequency

Figure 8 shows the non-dimensional calibration chart. The solid line represents the correlation fit of Eq. (6). The markers represent measurements at varying oscillation frequency $2 \pi \omega_{0}$ between 10 and $40 \mathrm{~Hz}$. The OHW enables the measurement of negative velocity for $-1 \leq U / \omega_{o} x_{o}$. For an oscillation frequency between 30 and $40 \mathrm{~Hz}$, this corresponds to a maximum measurable negative velocity of roughly $-1 \mathrm{~m} / \mathrm{s}$. In the positive velocity range, the OHW velocity $U^{\prime}$ equals the reference velocity.

To obtain the catalyst velocity distribution, consecutive measurements are performed in roughly 400 locations in a measurement plane $25 \mathrm{~mm}$ downstream of the catalyst outlet face, within a shrouded section to avoid entrainment. Figure 1 (right) shows the coordinate system in the measurement plane that is used for the velocity distribution plots in $\S 3.3$. The OHW device is mounted on a Dantec type $41 \mathrm{T50}$ automated positioning system, featuring a positioning accuracy of better than $0.25 \mathrm{~mm}$.

A PC equipped with a dSpace ${ }^{\mathrm{TM}} \mathrm{DS} 1103$ data acquisition board is used to trigger the velocity measurement and control the oscillator frequency $f_{o}$ with the fixed proportionality factor $R_{f}$ to the engine speed. The dSpace system reads the engine crankshaft position using a highresolution incremental encoder (angular error below $0.1^{\circ} \mathrm{ca}$ ), and the oscillator drive shaft angle using an optical encoder. 


\subsection{Data reduction}

Ensemble averaging is applied to obtain the phase-locked velocity distributions. As described in $\$ 2.3$, one ensemble is constructed from data obtained during crankshaft angle windows of valid OHW measurements in several consecutive engine cycles. Valid OHW measurements are possible when the relative velocity $U_{\text {rel }}$ seen by the moving hot-wire probe is positive, or during $-\arccos \alpha \leq \omega_{o} t+2 \pi n \leq \arccos \alpha(n \in \square)$. The obtained instantaneous OHW velocity in one particular point $\left(x_{i}, y_{i}\right)$ is $U_{i j e}^{\prime}\left(x_{i}, y_{i}, \theta_{j}, e\right)=U_{r e l}+U_{p}$, where subscripts $i=$ grid point index, $j=$ crankshaft angle index and $e=$ ensemble index. $U_{i j e}^{\prime}$ is converted to $U_{i j e}$ using the calibration function defined in Eq. (6) and the appropriate parameters $a$ and $b$.

The resulting ensembles of $U_{i j e}\left(x_{i}, y_{i}, \theta_{j}, e\right)$ are ensemble-averaged to obtain the timeresolved velocity $U_{i j}\left(x_{i}, y_{i}, \theta_{j}\right)$ :

$$
U_{i j}\left(x_{i}, y_{i}, \theta_{j}\right)=\frac{1}{E} \sum_{e=1}^{E} U_{i j e}\left(x_{i}, y_{i}, \theta_{j}, e\right)
$$

where $E=$ number of ensembles. Approximately 100 ensembles yield sufficient accuracy on the time-resolved velocity. More ensembles are needed when compared to the previous measurements on the isothermal flow rig. This is due to cycle-by-cycle variation, a phenomenon typical of internal combustion engine flows. Because of the absence of a combustion process, the CME flow rig is less affected by cyclic variation than a fired engine. Nevertheless, four times more ensembles are required when compared to the isothermal flow rig experiments to obtain an accuracy of $1 \%$ on the time-averaged mean velocity.

The time-averaged velocity $U_{i}\left(x_{i}, y_{i}\right)$ is defined as:

$$
U_{i}\left(x_{i}, y_{i}\right)=\frac{1}{J} \sum_{j=1}^{J} U_{i j}\left(x_{i}, y_{i}, \theta_{j}\right)
$$

where $J=$ number of crankshaft positions, which is determined by the sampling frequency. Regardless of engine speed, 256 samples are taken in each engine cycle. For instance at 2400 $\mathrm{rpm}$, this requires a sampling frequency of $5120 \mathrm{~Hz}$. Roughly 2.5 times more samples per engine cycle are taken when compared to previous measurements, due to the presence of blowdown and Helmholtz fluctuations, causing strong transients in the time-resolved velocity.

The mean (or spatial averaged) velocity $U_{m j}\left(\theta_{j}\right)$ is defined as:

$$
U_{m j}\left(\theta_{j}\right)=\frac{1}{A} \sum_{i=1}^{I} U_{i j}\left(x_{i}, y_{i}, \theta_{j}\right) A_{i}\left(x_{i}, y_{i}\right)
$$


where $I=$ number of grid points, $A_{i}=$ cross-sectional area of grid cell $i\left[\mathrm{~m}^{2}\right], A=$ total crosssectional area $=\sum_{i=1}^{I} A_{i}\left[\mathrm{~m}^{2}\right]$. The time-averaged mean velocity $U_{m}$ is defined as:

$$
U_{m}=\frac{1}{J} \sum_{j=1}^{J} U_{m j}\left(\theta_{j}\right)=\frac{Q}{A}
$$

where $Q=$ volumetric flow rate through the catalyst $\left[\mathrm{m}^{3} / \mathrm{s}\right]$. In all subsequent figures of velocity distributions, the non-dimensional velocity $\tilde{U}[-]$ is plotted, defined as $\tilde{U}=U / U_{m}$. The tilde $(\sim)$ is omitted in the figures.

The flow uniformity measure $\eta_{M}[-]$ is defined as the ratio of mean to maximum velocity. The absolute value of the velocity is used in the calculation of $\eta_{M}$. Eq. (11) gives the definitions of $\eta_{M}$ for a time-averaged and time-resolved velocity distribution:

$$
\left\{\begin{array}{c}
\eta_{M}=\left|U_{m}\right| / \max _{i=1 \ldots I}\left(\left|U_{i}\right|\right) \\
\eta_{M}(\theta)=\left|U_{m}(\theta)\right| / \max _{i=1 \ldots I}\left(\left|U_{i}(\theta)\right|\right)
\end{array}\right.
$$

The flow uniformity $\eta_{M}$ equals unity for an ideally uniform flow distribution (i.e. $U_{i}=U_{m}$ ), and varies between zero and unity otherwise. Weltens et al. [16] introduced the widely used flow uniformity index $\eta_{W}[-]$ based on the relative variance of the velocity distribution:

$$
\eta_{W}=1-\frac{1}{2\left|U_{m}\right| A} \sum_{i=1}^{I}\left|U_{i}-U_{m}\right| A_{i}
$$

The mean velocity appears in the denominator of Eq. (12), thus the value of $\eta_{W}(\theta)$ is undefined when $U_{m}(\theta)$ is zero. As such, $\eta_{w}$ is only given for time-averaged distributions.

\section{Experimental results}

\subsection{OHW}

To assess the effectiveness of the OHW system, a number of engine operating points that feature reverse flow are selected. In these operating points, the oscillator frequency $R_{f}$ is increased from zero for a stationary probe to the maximum attainable. As $R_{f}$ increases, so does the resolution in the negative velocity range, and consequently the correspondence improves between the exhaust flow rate calculated as the area-averaged $\mathrm{OHW}$ velocity distribution and the intake flow rate measured using the laminar flow meter.

Figure 9 (left) shows the non-dimensional flow rate deviation $\delta Q=Q / Q_{\text {ref }}-1$ [-]. The reference exhaust flow rate $Q_{r e f}\left[\mathrm{~m}^{3} / \mathrm{s}\right]$ is calculated as $Q_{r e f}=\rho_{s}\left(Q_{s, i n}-Q_{s, b b}\right) / \rho$, where $\rho_{s}$ 
and $\rho$ are the density of air at standard conditions $\left(0^{\circ} \mathrm{C}, 1 \mathrm{~atm}\right)$ and exhaust conditions. The intake standard flow rate $Q_{s, i n}$ is determined by means of a laminar flow meter in the intake system. This measurement is further verified using a cylinder pressure sensor, by calculating the cylinder charge per cycle from the pressure rise during the compression stroke. The blowby leakage standard flow rate $Q_{s, b b}$ is estimated based on a correlation as a function of engine speed, time-averaged cylinder pressure and temperature. At most, blow-by leakage amounts to $5 \%$ of intake flow rate, for full load at low engine speed.
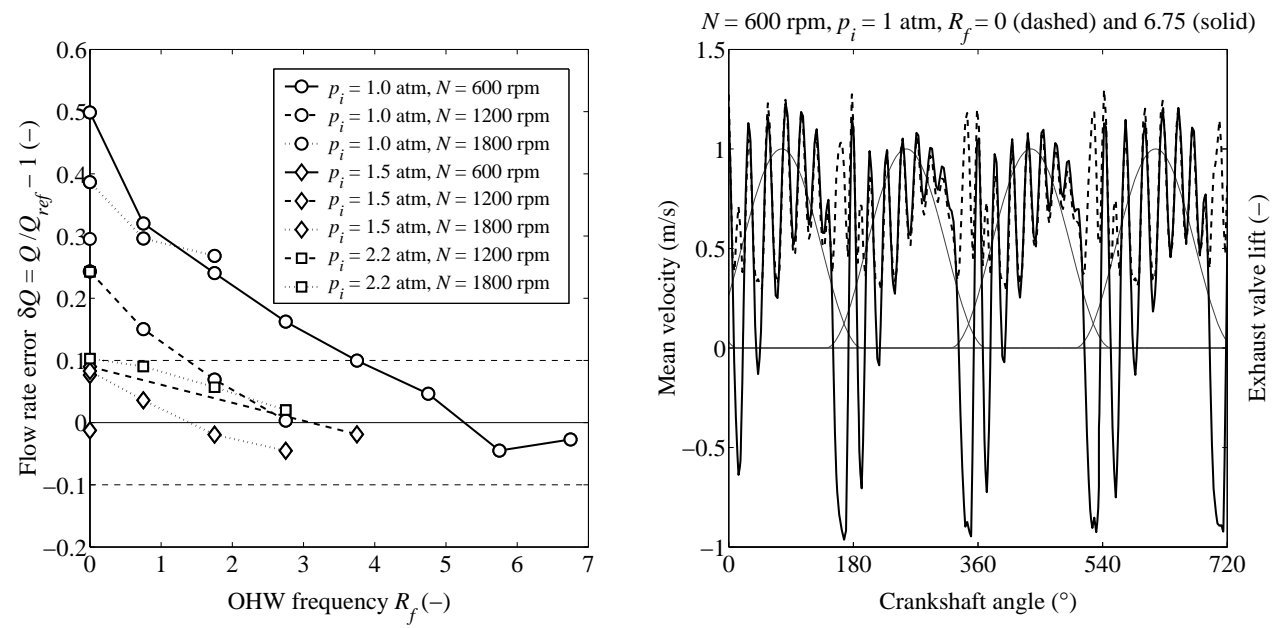

\section{Figure 9. Influence of OHW frequency $R_{f}$ on flow rate deviation (left) and time-resolved mean velocity (right)}

The markers in Fig. 9 (left) represent experiments at engine speeds of 600, 1200 and 1800 rpm. At low engine load $\left(p_{i}=1.0 \mathrm{~atm}\right), \S 3.3$ demonstrates that strong backflow occurs. This situation is not physically possible with fired engine conditions. However, local occasional backflow occurs also at higher engine load $\left(p_{i}=1.5 \ldots 2.2 \mathrm{~atm}\right)$, where positive blowdown and displacement flows exist.

Figure 9 (left) shows that for increasing OHW oscillation frequency $R_{f}$, the velocity measurement becomes increasingly more accurate. Traditional HWA using a stationary probe corresponds in Fig. 9 (left) to the points at $R_{f}=0$. The flow rate error amounts to anywhere between 0 and $50 \%$. The OHW approach has reduced the flow rate error to within the accuracy margins on $Q_{r e f}(5$ to $10 \%)$

Figure 9 (right) shows the influence of using the OHW on the time-resolved mean velocity $U_{m}(\theta)$. The dashed line uses a stationary probe $\left(R_{f}=0\right)$, whereas the solid line uses an oscillating probe at $R_{f}=6.75$. This experiment corresponds to the rightmost circular marker in Fig. 9 (left). The mean velocity using traditional HWA $\left(R_{f}=0\right)$ exhibits the typical rectification or folding, as HWA is insensitive to the velocity direction, only to its magnitude.

Note that the mean velocity fluctuations in Fig. 9 (right) during the displacement phases are due to Helmholtz resonances in the exhaust runners and collector volume. This is explained in §3.2. No significant reverse flow occurs during the latter part of the displacement phase. 
During those periods, Fig. 9 (right) shows that the OHW velocity at $R_{f}=0$ and $R_{f}=6.75$ yield identical results.

\subsection{Helmholtz resonances}

The time-resolved mean velocity $U_{m}(\theta)$ features strong fluctuations when compared to previous measurements on an isothermal flow rig [1]. This is due to the two-stage nature of the exhaust stroke, combined with the Helmholtz resonance effect. Figure 10 gives a comparison at equal engine speed and flow rate $\left(\cong 100 \mathrm{~m}^{3} / \mathrm{h}\right)$ between the mean velocity on the CME (left) and isothermal (right) flow rig. The comparison is presented here since an isothermal flow rig approach is used by numerous authors $[1,3,5,6,7]$ for studying pulsating flow in exhaust systems with close-coupled catalyst.
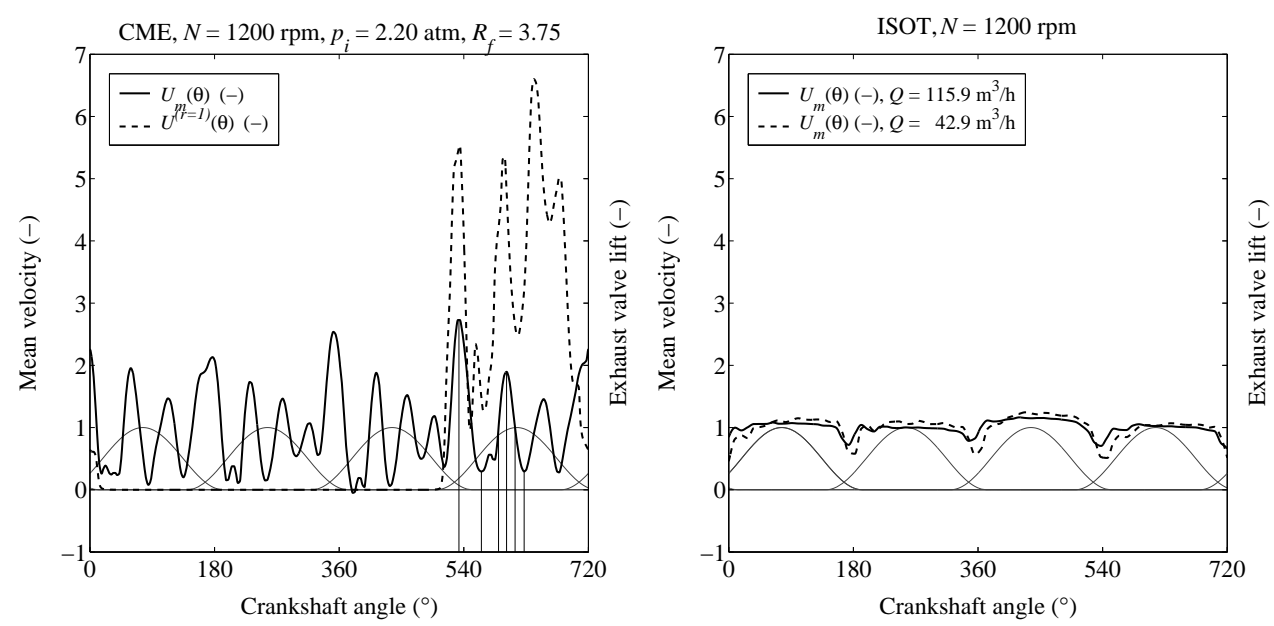

Figure 10. Time-resolved velocity on CME (left) and isothermal flow rig [1] (right), for comparable engine speed and flow rate $\left(\cong 100 \mathrm{~m}^{3} / \mathrm{h}\right)$
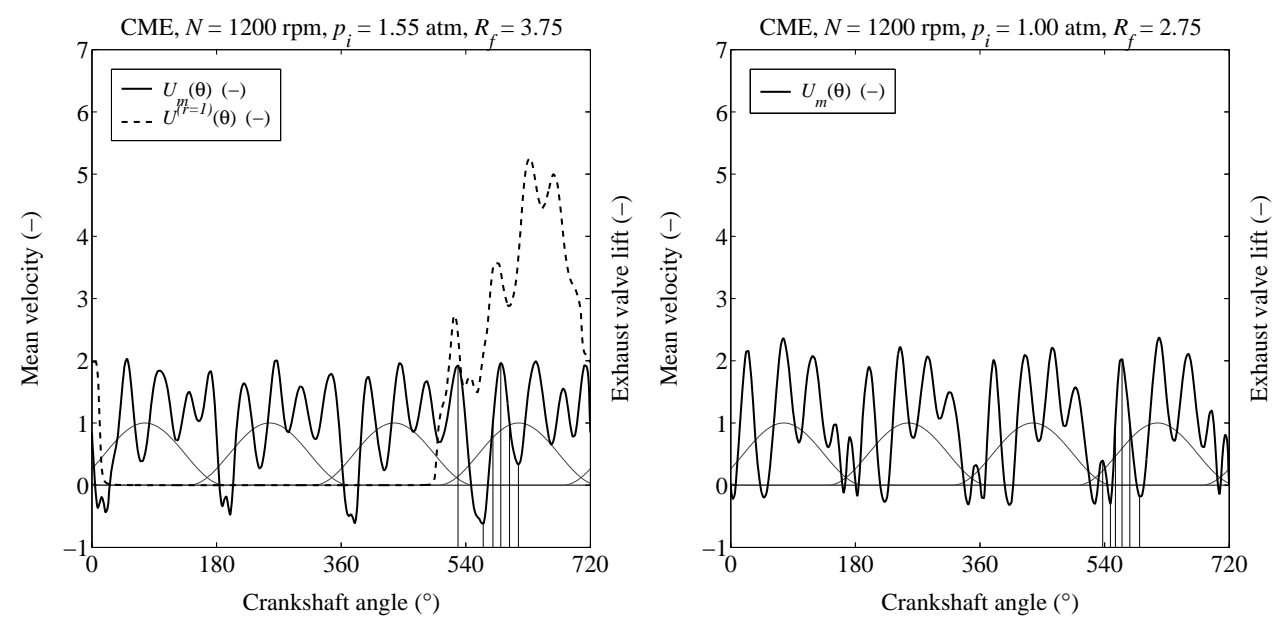

Figure 11. Time-resolved velocity in part (left) and zero (right) load conditions on CME flow rig 
Figs. 10 (left) and 11 (left) show the time-resolved velocity in runner \#1 $U^{(r=1)}(\theta)$ (dashed line). Since $0{ }^{\circ} \mathrm{ca}$ corresponds to top dead centre of cylinder $\# 1$ and considering the engine's firing order, the plots show the exhaust strokes of cylinders \#3, \#4,\#2 and \#1. The six vertical lines during the exhaust stroke of cylinder \#1 indicate the crankshaft positions (a) through (f) for which the time-resolved velocity distributions are shown in $\S 3.3$ (Figs. 17 and 18).

The runner velocity is measured at the inlet of runner \#1 using a hot-film sensor, mounted flush with the inner wall. $U^{(r=1)}$ is measured in a single point, and as such it is only indicative of the mean runner velocity. It is used to determine the phase lag between runner and catalyst velocity, with respect to the Helmholtz resonance phenomenon.

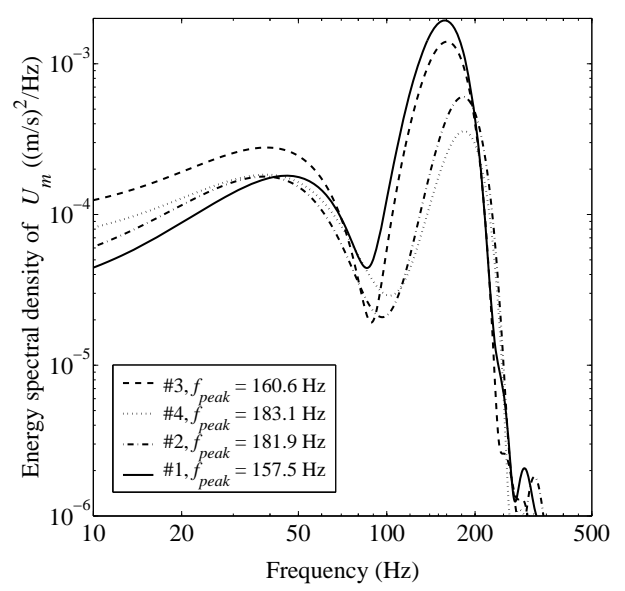

Figure 12. Spectra of time-resolved mean velocity during individual exhaust strokes on CME flow rig, for $N=600 \mathrm{rpm}$

Table 2. Catalyst mean velocity peak fluctuation frequencies

\begin{tabular}{ccccccc}
\hline \multirow{2}{*}{$N$} & \multicolumn{2}{c}{$p_{i}$} & \multirow{2}{*}{$Q_{\text {ref }}$} & \multicolumn{5}{c}{ Peak frequency [Hz] } \\
& & & $\# 1$ & $\# 2$ & $\# 3$ & $\# 4$ \\
{$[\mathrm{rpm}]$} & {$[\mathrm{atm}]$} & {$\left[\mathrm{m}^{3} / \mathrm{h}\right]$} & {$[-]$} & {$[-]$} & {$[-]$} & {$[-]$} \\
\hline 1200 & 1.00 & 46.6 & 164 & 181 & 166 & 178 \\
\hline 1200 & 1.55 & 67.7 & 141 & 153 & 126 & 161 \\
\hline 1800 & 1.00 & 75.1 & 148 & 158 & 143 & 144 \\
\hline 1200 & 2.23 & 93.3 & 125 & 173 & 141 & 158 \\
\hline 1800 & 1.58 & 97.4 & 152 & 165 & 141 & 169 \\
\hline 1800 & 2.23 & 136.6 & 143 & 146 & 139 & 144 \\
\hline 2400 & 1.55 & 192.1 & 135 & 193 & 125 & 195 \\
\hline 2400 & 2.03 & 238.8 & 140 & 193 & 153 & 178 \\
\hline $\begin{array}{l}\text { Helmholtz resonance } \\
\text { frequency } f_{H, 1}\left(\text { at } 20^{\circ} \mathrm{C}\right)\end{array}$ & 166 & 188 & 166 & 188 \\
\hline $\begin{array}{l}\text { Helmholtz resonance } \\
\text { frequency } f_{H, 2}\left(\text { at } 20{ }^{\circ} \mathrm{C}\right)\end{array}$ & 182 & 205 & 182 & 205 \\
\hline
\end{tabular}

The mean velocity fluctuations in Figs. 9 through 11 during the displacement phases have been observed previously on an isothermal flow rig [1], although to a much lesser extent. The 
fluctuation frequencies observed on $\mathrm{CME}$ and isothermal flow rig are identical, varying between 140 and $200 \mathrm{~Hz}$. The frequency is independent of engine speed or flow rate, as the summary in Table 2 shows. The values $f_{H, 1}$ and $f_{H, 2}$ are discussed below.

Figure 12 shows frequency spectra of $U_{m}$ during each cylinder's exhaust stroke for $N=600$ rpm. As Table 2 indicates, the peak frequency remains unchanged at higher engine speeds. However, the spectral resolution decreases as the engine speed increases, which leads to increasing uncertainty on the peak frequencies.

A Helmholtz resonator consists of a volume connected to a pipe, behaving as a spring-andmass system. The gas in the pipe behaves as an incompressible plug with mass $m=\rho A L$ $[\mathrm{kg}]$, where $A$ and $L=$ cross-sectional area $\left[\mathrm{m}^{2}\right]$ and length $[\mathrm{m}]$ of the pipe. The compressible volume $V$ is characterised by a spring constant $k=\kappa p A^{2} / V[\mathrm{~N} / \mathrm{m}]$, where $\kappa=$ ratio of specific heats [-]. This system features an eigenfrequency $f_{H}[\mathrm{~Hz}]$ :

$$
f_{H}=\frac{1}{2 \pi} \frac{c}{L} \sqrt{\frac{A L}{V}}
$$

where $c=$ speed of sound $[\mathrm{m} / \mathrm{s}]$. A Helmholtz resonator is usually a cavity consisting of a closed volume and a pipe perpendicular to the main flow duct, without net flow through the pipe. Such resonators are used as sound sources in musical instruments, or as acoustic dampers (e.g. in exhaust mufflers). Here, the same resonating behaviour is observed, yet for a system that features net flow. The Helmholtz frequency $f_{H}$ denotes the zeroth order gas dynamic resonance frequency of the system.

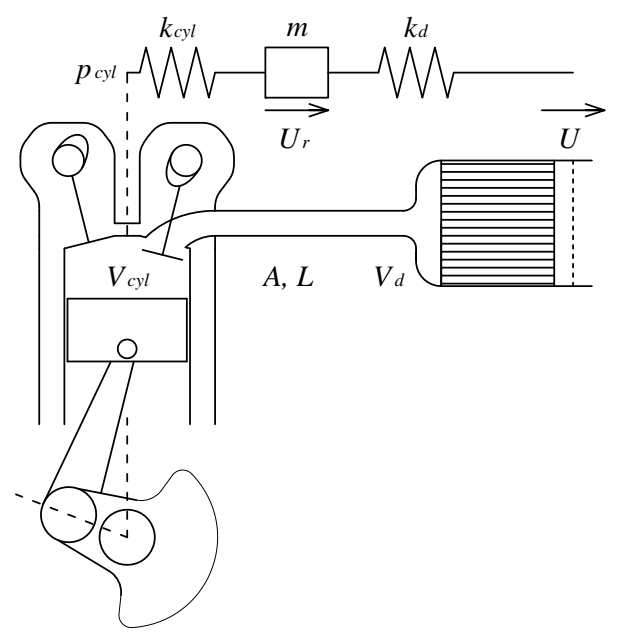

\section{Figure 13. Lumped model of Helmholtz resonance in CCC exhaust manifold}

Up-close examination of the velocity in runner \#1 and the catalyst (dashed versus solid lines in Figs. 10 (left) and 11 (left)) reveals that the runner velocity leads the catalyst velocity by $\pi / 2$ radians. The cylinder pressure is not shown, yet also leads the catalyst velocity by $\pi / 2$ radians. This phase lag is characteristic of a Helmholtz resonator as indicated in the schematic diagram in Fig. 13. The gas in the open exhaust runner oscillates as incompressible plug. 
Since the runners extend into the cylinder head up to the exhaust valves, the lengths in Table 1 are increased by roughly $90 \mathrm{~mm}$. The diffuser volume $V_{d}$ and cylinder volume $V_{c y l}$ act as two compressible springs in series. In terms of Eq. (13), this corresponds to using an effective volume $V$ defined as $1 / V=1 / V_{d}+1 / V_{c y l}$. The cylinder volume can be approximated by $V_{c y l}=V_{0}+\frac{1}{2} s \pi b^{2} / 4$ corresponding to the mid piston position, where $V_{0}=$ dead volume, $b$ and $s=$ cylinder bore and piston stroke.

Using the above effective volume, Eq. (13) yields the values $f_{H, 2}$ in Table 2, slightly overestimating the resonance frequency. Upon neglecting the diffuser volume compressibility, the effective volume reduces to the cylinder volume, yielding the values $f_{H, 1}$ in Table 2 . These agree better with the experiments, however the assumption that the diffuser volume is incompressible contradicts the observed phase difference between runner and catalyst velocity. This cannot be readily explained, yet might be attributed to the crude approximation of the lumped parameter model.

The exhaust stroke of each individual cylinder features a different resonance frequency, based on each runner's length. Table 2 gives an overview of measured peak frequencies of the timeresolved mean velocity, for each cylinder's exhaust stroke and the corresponding Helmholtz eigenfrequencies $f_{H}$, determined using Eq. (13) as described above.

A one-dimensional gas dynamic model of the exhaust manifold is used to further verify the

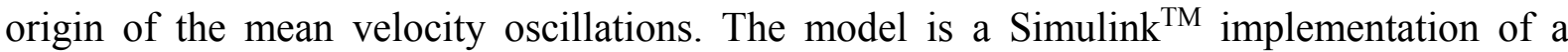
second order total variation diminishing (TVD) differencing scheme to simulate unsteady compressible one-dimensional flow in the exhaust runners. The model incorporates the TVD flux differencing technique by Vandevoorde et al. [18]. A grid spacing of $5 \mathrm{~mm}$ is applied in each runner. The diffuser is modelled as zero-dimensional compressible volume. The catalyst monolith is modelled as a restriction with coefficients based on pressure drop experiments in steady flow. The inertia of the gas in the monolith is taken into account.
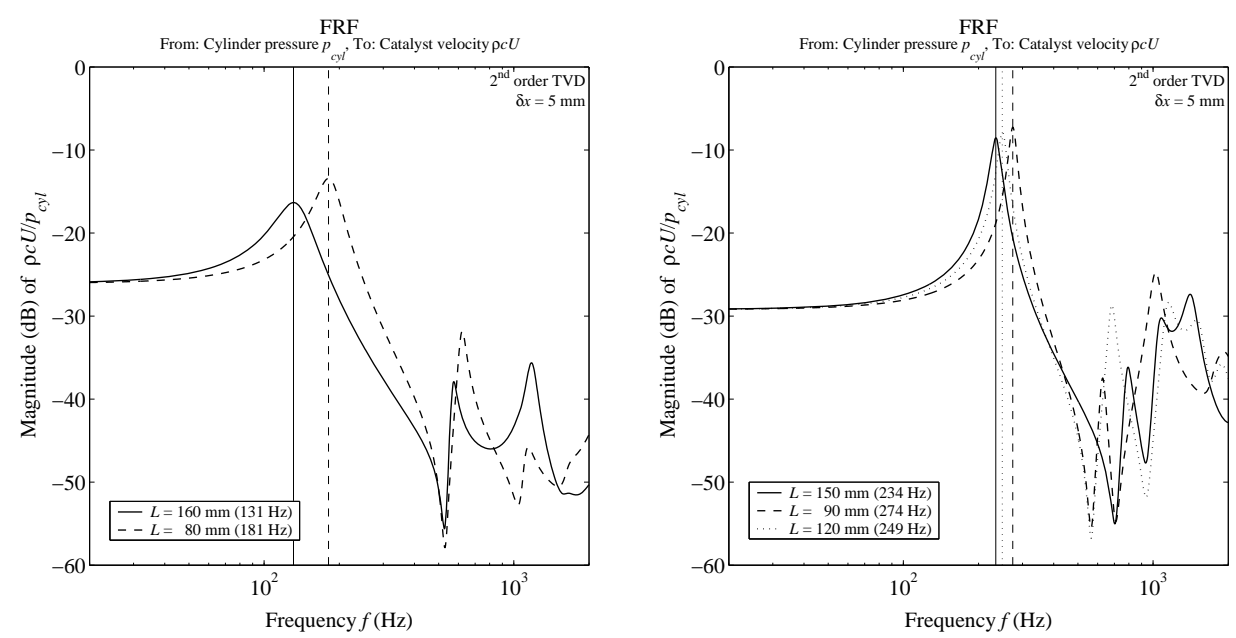

Figure 14. Frequency response functions from cylinder pressure to catalyst velocity for exhaust manifold under investigation (left) and manifold A [1] (right) 
Figure 14 shows numerically determined frequency response functions (FRF) from the cylinder pressure $p_{c y l}[\mathrm{~Pa}]$ (relative to atmospheric conditions) to the catalyst velocity $U[\mathrm{~m} / \mathrm{s}]$. The FRF is non-dimensionalised using $\rho c[\mathrm{~Pa} /(\mathrm{m} / \mathrm{s})]$. Figure 14 shows the FRF of the manifold under investigation (left) and manifold A (right), which has been used in previous experiments [1] and is included here since an improved gas dynamic model is used [1]. Peaks at frequencies above $1 \mathrm{kHz}$ represent acoustic resonances, due to standing wave effects. The Helmholtz resonance frequencies in Fig. 14 (left) are comparable to the frequency $f_{H}$ from Eq. (13), and to the frequencies in Table 2 observed on the CME flow rig.

Adam et al. [8] present numerical results for a one-dimensional gas dynamic model of a closecoupled catalyst exhaust manifold, mounted on a fired engine. Figure 9 in their paper shows the velocity in each exhaust runner for $3000 \mathrm{rpm}$ at part load. The velocity fluctuations during the displacement phases are very similar to the time-resolved catalyst velocity observed on the CME flow rig. However, fluctuations in their catalyst velocity are much less pronounced compared to the CME flow rig. The fluctuation frequencies during each cylinder's exhaust stroke differ, depending on the runner length. The estimated fluctuation frequency is $450 \mathrm{~Hz}$ for the long runners \#1 and \#4 and $580 \mathrm{~Hz}$ for the short runners \#2 and \#3. Based on these estimates, the ratio of the length of long to short runners is 1.6 , which seems plausible from their paper.

Park et al. [10] present experimental results using LDA for a close-coupled catalyst exhaust manifold, mounted on a fired engine. Figure 5 in their paper shows the velocity in runner \#3 for $2000 \mathrm{rpm}$ at part load. Substantial backflow occurs following blowdown, as is observed on the CME flow rig. The estimated fluctuation frequency is $300 \mathrm{~Hz}$. This frequency is too low to be caused by pressure waves as explained by the authors, yet the value corresponds well with a Helmholtz resonance of the manifold.

Liu et al. [9] present numerical results for a close-coupled catalyst manifold in fired engine conditions, obtained using a combined one-dimensional and three-dimensional numerical approach similar to Adam et al. [8]. Figure 7 [9] shows the runner velocity at $3000 \mathrm{rpm}$ and full load. The estimated frequency of the fluctuations during the displacement phase is 310 Hz. Simulation results in Fig. 8 [9] indicate no fluctuations in motored engine conditions. This is unexpected if the Helmholtz resonance assumption stated above is correct. Perhaps the motored and fired cases do not exhibit the same excitation required to invoke the resonance effect. Figure 9 shows numerical and experimental results using LDA, downstream of the catalyst. Reverse flow occurs following blowdown. Although no actual blowdown occurs in motored conditions at atmospheric intake pressure, reverse flow is nonetheless detected in experiments and simulations. For fired conditions, only the simulations show reverse flow.

Benjamin et al. [11] present LDA measurements downstream of a close-coupled catalyst, in a fired engine at $2000 \mathrm{rpm}$ and high load. Similar to Liu et al. [65], the experimental results are compared to a transient CFD simulation, coupled with a commercial one-dimensional gas 
dynamics code. Figure 8 in [11] shows a comparison between measured (cross markers) and calculated (solid line) runner velocity. The simulation exhibits significant velocity fluctuations during the displacement phase. The fluctuation frequency is about $375 \mathrm{~Hz}$ for the numerical model, which agrees with other fired engine studies [8, 9], whereas the measurement shows a frequency of about $200 \mathrm{~Hz}$.

Eq. (13) shows that the resonance frequency $f_{H} \propto c \propto \sqrt{T}$. Since the temperature ratio is roughly four between fired and CME conditions, the resonance frequency is two times higher (for the same geometry) in fired engine conditions compared to the CME flow rig. This agrees with the observed frequencies in the literature [8, 9, 10], ranging between 300 and $600 \mathrm{~Hz}$.

In conclusion, the velocity fluctuations during the displacement phases observed on the CME flow rig are found in similar exhaust systems in fired engine conditions, both experimentally and numerically.

\subsection{Reverse flow}

For an engine speed of $1200 \mathrm{rpm}$ and engine load varying between zero, part and full load, Figs. 15 through 18 present time-averaged and time-resolved catalyst velocity distributions measured on the CME flow rig. These representative figures show the spatial and temporal occurrence of reverse flow through the catalyst.

Figure 15 shows on top the time-averaged velocity distributions, and below the corresponding time-resolved mean velocity and flow uniformity according to Eq. (11). Velocity is nondimensionalised using the time-averaged mean velocity. Velocity distributions are plotted as contour lines, where the corresponding velocity is indicated by the labels and in the vertical velocity scale to the right of each plot. The dashed and dotted contour lines represent unity and zero velocity respectively. Regions of reverse flow below the dotted contour line are shaded. Each velocity distribution plot contains a plot of $U_{y=0}[-]$, the velocity along the line $y$ $=0$. Figs. 15 and 16 show that the flow uniformity decreases as the engine load increases, or equivalently the flow rate increases.

Figs. 17 and 18 show the evolution of the time-resolved velocity distribution as a function of crankshaft position during the exhaust stroke of cylinder \#1, for zero, part and full load. As reference, Fig. 16 shows the catalyst velocity obtained for steady flow through runner \#1, at the flow rate corresponding to Figs. 17 and 18.

The crankshaft positions shown in Figs. 17 and 18 correspond to characteristic events during the exhaust stroke of cylinder \#1: (a) maximum $U_{m}(\theta)$ during blowdown, (b) minimum $U_{m}(\theta)$ following blowdown, (c) increasing $U_{m}(\theta)=1$ during displacement, (d) first maximum $U_{m}(\theta)$ during displacement, (e) decreasing $U_{m}(\theta)=1$ during displacement and (f) first minimum $U_{m}(\theta)$ during displacement. The crankshaft positions corresponding to 

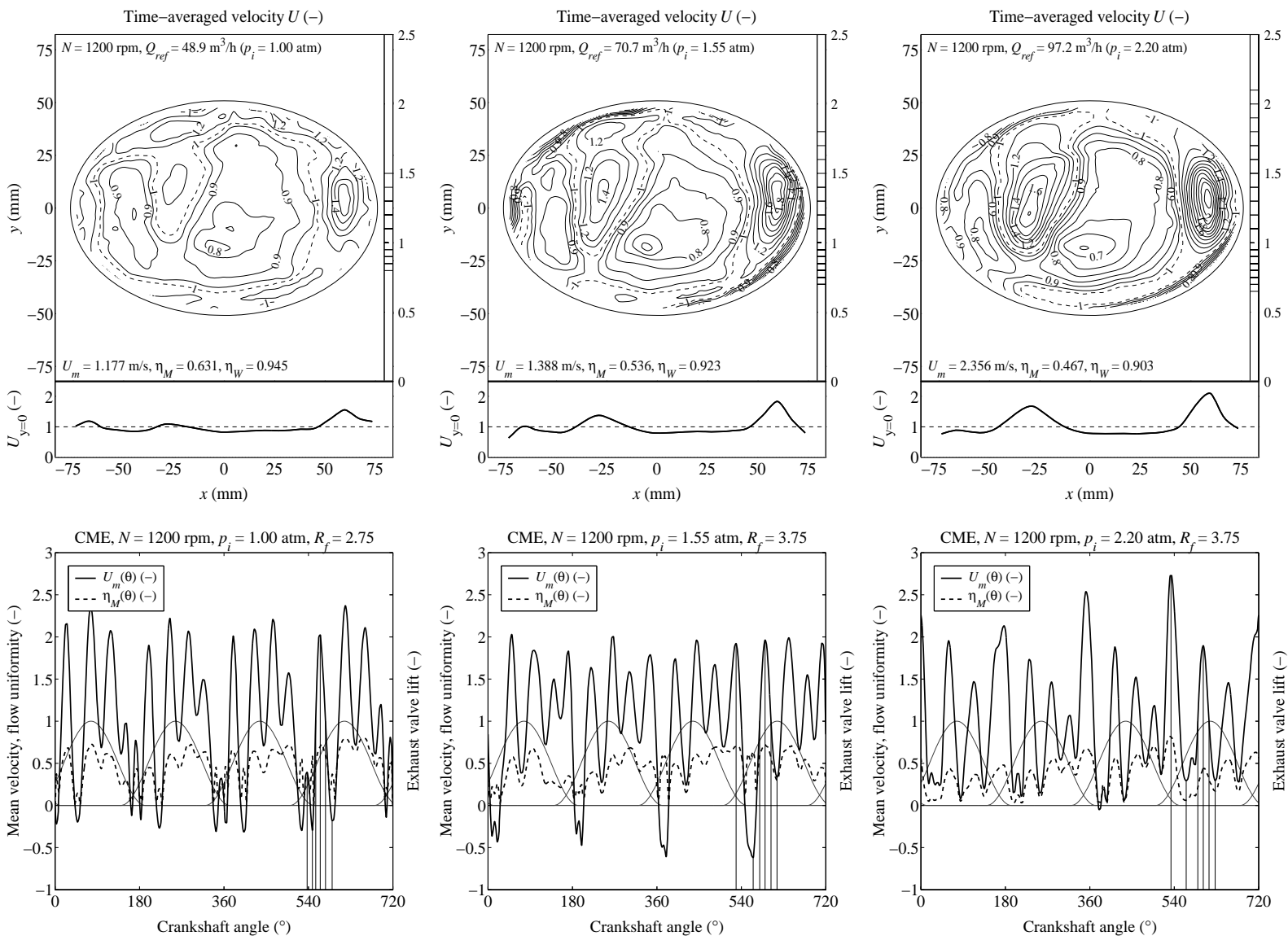

Figure 15. Time-averaged catalyst velocity (top) and time-resolved mean catalyst velocity and flow uniformity (bottom) for $1200 \mathrm{rpm}$ at zero (left), part (middle) and full (right) load
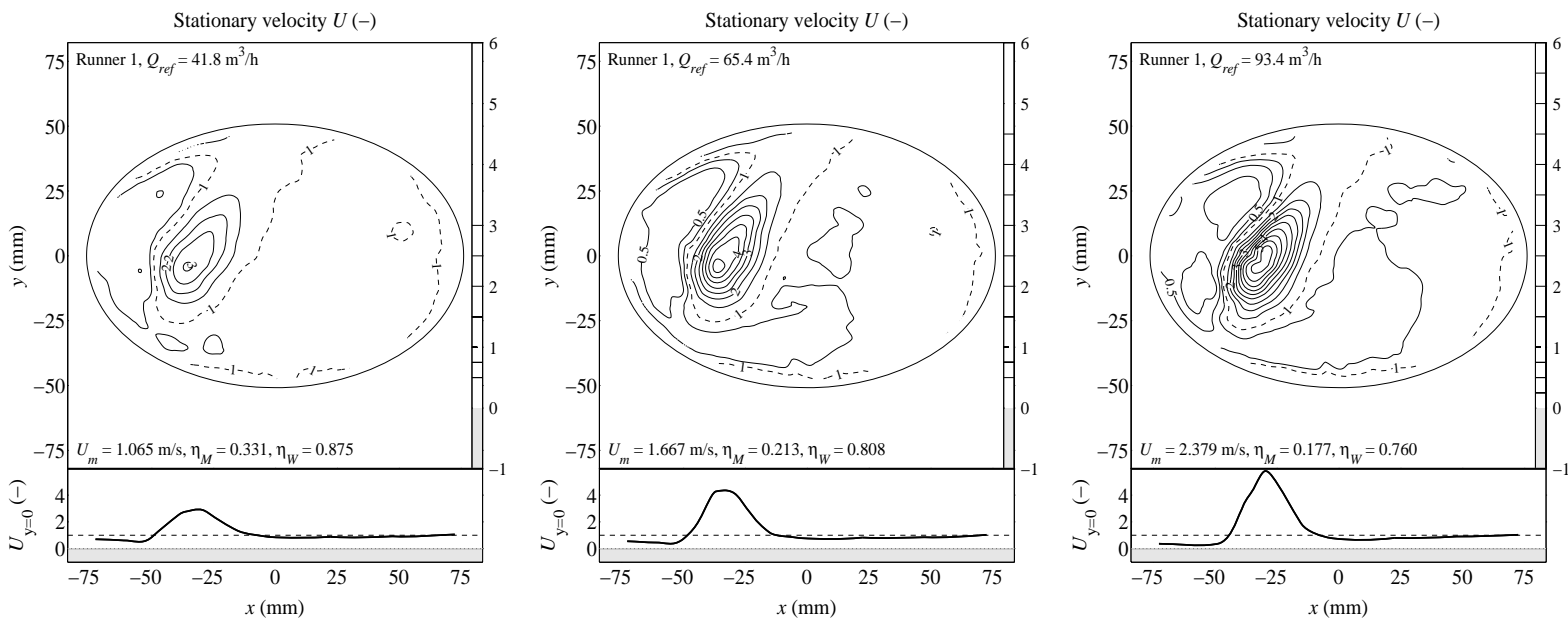

Figure 16. Stationary catalyst velocity for steady flow through runner \#1 at flow rates corresponding to zero (left), part (middle) and full (right) load in Fig. 15 

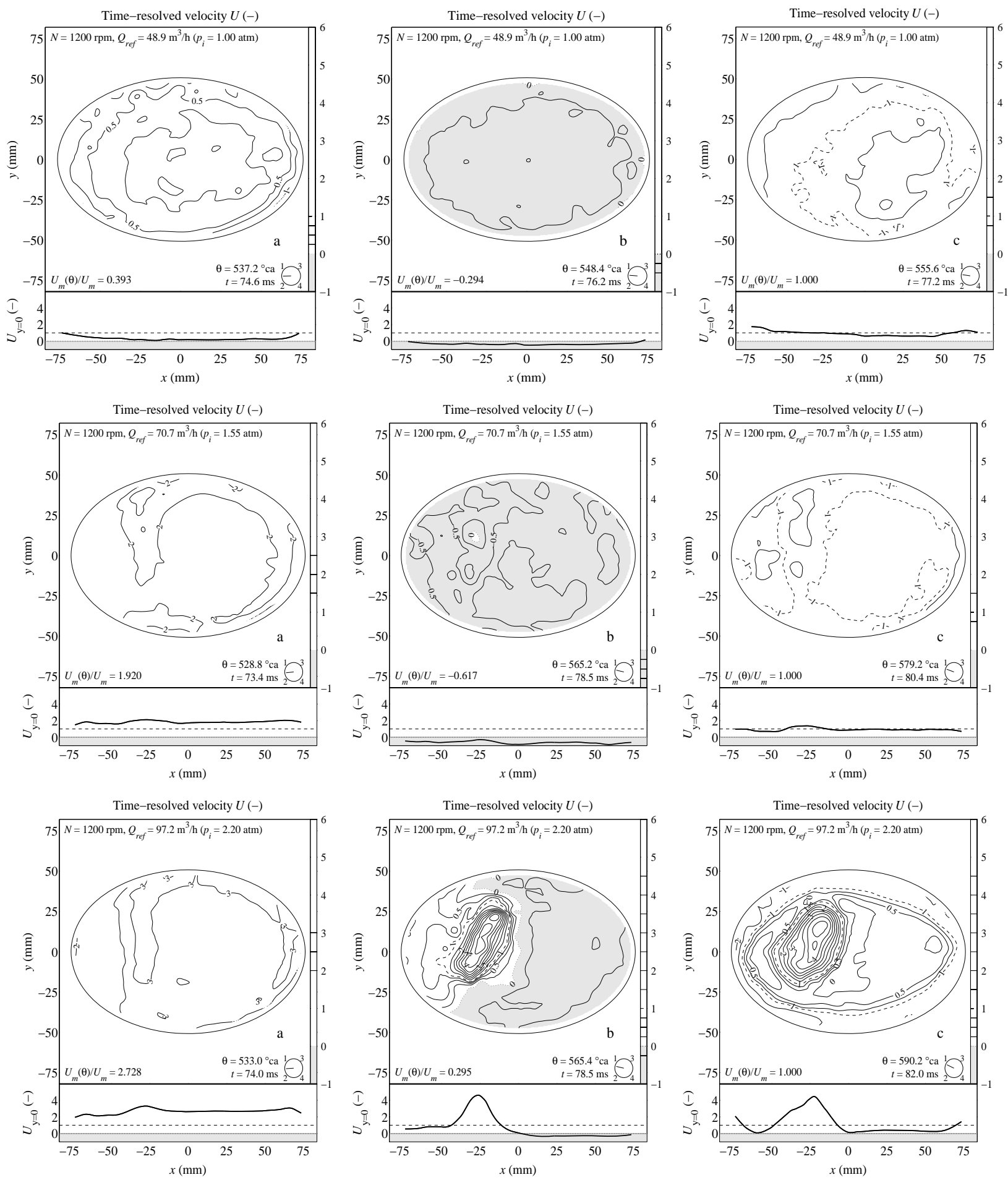

Figure 17. Time-resolved catalyst velocity for $1200 \mathrm{rpm}$ at zero, part and full load (top to bottom), at crankshaft positions a, b, c (left to right) 

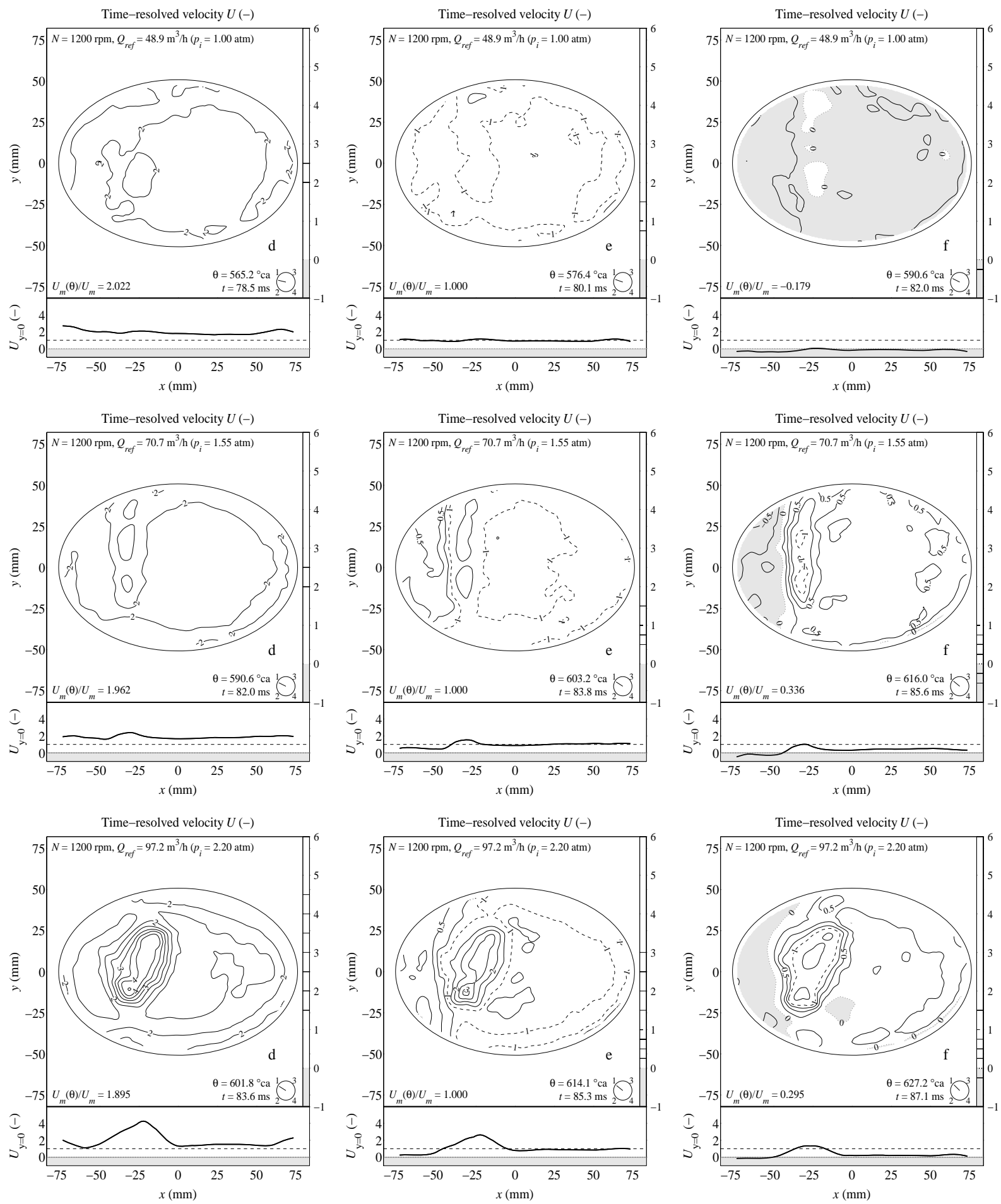

Figure 18. Time-resolved catalyst velocity for $1200 \mathrm{rpm}$ at zero, part and full load (top to bottom), at crankshaft positions $d, e, f$ (left to right)

these events are indicated in the plots in Figs. 17 and 18, and can be determined from the evolution of the time-resolved mean velocity $U_{m}(\theta)$ in Fig. 15 (bottom). The six vertical lines in Figs. 10, 11 and Fig. 15 (bottom) correspond to the positions (a) through (f). 
During the first part of the blowdown (Fig. 17 (left)), the velocity increases while the flow uniformity remains quite high. The second part of the blowdown (Fig. 17 (centre)) differs according to the engine load. For high engine load, the distribution is characterised by a sharp velocity peak where runner \#1 issues into the catalyst, and extensive backflow throughout the remainder of the catalyst. Backflow occurs even for high load conditions.

During the subsequent displacement phase, the mean velocity increases as the piston starts expelling the cylinder charge (Fig. 17 (right)). The peak velocity at high engine load decreases only gradually (Fig. 17 (bottom)). Due to the Helmholtz resonance in the manifold, the mean velocity $U_{m}(\theta)$ continues to fluctuate throughout the displacement phase. Figure 18 (left, centre, right) shows the evolution from the first maximum to the first minimum during the displacement phase. Although the first minimum occurs roughly simultaneously to the maximum piston velocity, reverse flow still occurs (Fig. 18 (right)). It is however less pronounced when compared to the post-blowdown flow reversal (Fig. 17 (centre)).

Park et al. [10] present phase-locked velocity results obtained using LDA in a CC manifold on a fired engine. In their paper, Figures 7 and 8 show periodic reverse flow in the order of -1 to $-2 \mathrm{~m} / \mathrm{s}$, that occurs following each blowdown.

Also using LDA, Liu et al. [9] show reverse flow occurring downstream of a CC catalyst in motored engine conditions. Transient simulations show reverse flow in motored and fired conditions. Equivalently, reverse flow is most pronounced following blowdown. The maximum backflow varies between -1 and $-5 \mathrm{~m} / \mathrm{s}$ in motored and fired conditions.

Transient simulations by Benjamin et al. [11] predict strong backflow in the runner, following the blowdown (see Fig. 8 in [11]). Figures 10, 11 and 12 in [11] show a qualitative correspondence between the numerical and LDA results for the catalyst velocity. Backflow is measured in the catalyst in fired conditions, although weaker than predicted by the simulation. The simulation predicts a catalyst velocity between -5 and $22 \mathrm{~m} / \mathrm{s}$. The measured velocity at the same location exhibits a reduced backflow magnitude.

\section{Conclusion}

The current paper provides some new insights into the time-resolved flow dynamics of modern compact automotive exhaust manifolds with close-coupled catalyst. The focus is mainly on (i) the occurrence and explanation of strong Helmholtz resonances and (ii) the spatial and temporal occurrence of flow reversal in the catalyst.

The experiments are performed on a charged motored engine (CME) flow rig, which generates cold pulsating flow. Flow similarity between the CME and fired engine conditions is examined in $\S 2.2$, using an analytical analysis of non-dimensional mass flow rate, Reynolds and Mach number. Although CME and fired engine conditions are not identical, the cold 
pulsating flow does feature a two-stage exhaust stroke with blowdown and displacement phases, typical of fired engine conditions.

Oscillating hot-wire anemometry (OHW) has proven a useful approach for measuring bidirectional phase-locked velocity in the current application. $\$ 3.1$ demonstrates the significant improvement of using OHW when compared to traditional hot-wire anemometry in reversing flows.

Most velocity measurements have been performed downstream of the catalyst, without exit cone or tail pipe. The cold flow generated by the CME enables the use of hot-wire anemometry, resulting in a high spatial and temporal resolution. The level of detail obtained in this way is the major contribution of the current measurement technique over other experimental studies that use LDA on a CCC manifold in motored or fired engine conditions $[4,9,10,11,12]$ to obtain phase-locked velocity results in some points of the cross-section. As a drawback, the OHW technique is not applicable to measuring the flow field upstream of the catalyst, inside the runners or diffuser.

The displacement phase features mean catalyst velocity fluctuations at frequencies that are independent of engine speed and engine load or flow rate. These fluctuations are caused by a Helmholtz resonance effect that is intrinsic to the manifold geometry. Experimental results for the CME flow rig are in good agreement with simulations using a one-dimensional gas dynamic model of the exhaust manifold. Other sources in the literature mention mean catalyst velocity fluctuations during the displacement phase, for fired engine conditions. Although explanations regarding the origin of these fluctuations vary, the estimated frequencies seem to correspond very well to Helmholtz resonances observed in the current research.

Strong periodic reverse flow is observed throughout the catalyst cross-section, particularly following each blowdown phase. The extent to which reverse flow occurs is surprising, considering the substantial pressure drop created by the catalyst monolith. For the current experiments, no exit cone or tailpipe is used on the exhaust manifold. However, the occurrence of reverse flow cannot be solely attributed to the absence of the exit cone and its associated backpressure. Several other sources in the literature $[8,9,10,11,12]$ provide numerical and experimental results, demonstrating significant backflow in similar exhaust systems with exit cone.

\section{Appendix: flow similarity}

The analytical derivation below yields expressions for the peak mass flow rates during blowdown (Eq. (1)) and displacement phase (Eq. (2)). These expressions are used in the discussion of flow similarity in $\$ 2.2$ between the CME flow rig and a fired engine.

For this derivation, in-cylinder heat loss and blow-by leakage are neglected. Air is taken as working fluid, with thermodynamic properties evaluated at a fixed mean temperature. 
From the conservation of mass and energy result the following expressions describing the relation between intake and residual state:

$$
\frac{\rho_{e}}{\rho_{i}}=\frac{V_{i}}{V_{e}} ; \quad \frac{p_{e}}{p_{i}}=\left(\frac{V_{i}}{V_{e}}\right)^{\kappa}\left(1+\frac{\Delta T_{c}}{T_{i}}\left(\frac{V_{0}}{V_{i}}\right)^{\kappa-1}\right)
$$

where $\rho=$ density $\left[\mathrm{kg} / \mathrm{m}^{3}\right], p=$ pressure $[\mathrm{Pa}], V=$ cylinder volume $\left[\mathrm{m}^{3}\right], T=$ temperature $[\mathrm{K}]$ and the subscripts $i, e, 0$ respectively denote intake valve closing, exhaust valve opening and top dead centre. The adiabatic temperature rise due to combustion equals $\Delta T_{c}=\left(\phi S_{f}\right) /\left(c_{v} L_{f}\right)$, where $\phi=$ combined equivalence ratio and combustion efficiency [-], $S_{f}=$ lower heating value of fuel $[\mathrm{J} / \mathrm{kg}], c_{v}=$ specific heat capacity at constant volume $[\mathrm{J} / \mathrm{kgK}]$, $L_{f}=$ theoretical air-to-fuel ratio $[-]$.

The exhaust stroke is divided into blowdown and displacement phases. The blowdown phase is regarded as the expansion of the residual cylinder pressure under constant cylinder volume. The displacement phase is regarded as volumetric expulsion of gas at quasi-constant pressure. Assuming a constant cylinder volume, the state evolution with respect to the residual state (denoted with subscript $e$ ) is described by:

$$
\frac{\rho(\theta)}{\rho_{e}}=\frac{m(\theta)}{m_{e}} ; \quad \frac{p(\theta)}{p_{e}}=\left(\frac{m(\theta)}{m_{e}}\right)^{\kappa}
$$

where $\theta=$ crankshaft angle [rad].

Approximating the exhaust manifold pressure with the atmospheric pressure $p_{a}$, the following expression gives the mass flow rate over the exhaust valves assuming compressible restricted flow:

$$
\begin{aligned}
M(\theta) & =-\frac{\partial m}{\partial t}(\theta)=C_{d} n_{e} \pi d_{e} h_{e}^{\prime}(\theta) \frac{p(\theta)}{\sqrt{r T(\theta)}} f\left(\frac{p_{a}}{p(\theta)}\right) \\
f\left(\frac{p_{a}}{p}\right) & = \begin{cases}\left(\frac{p_{a}}{p}\right)^{1 / \kappa} \sqrt{\frac{2 \kappa}{\kappa-1}\left(1-\left(\frac{p_{a}}{p}\right)^{(\kappa-1) / \kappa}\right)} & ; \frac{p_{a}}{p}>\left(\frac{2}{\kappa+1}\right)^{\frac{\kappa}{\kappa-1}} \\
\sqrt{\kappa}\left(\frac{2}{\kappa+1}\right)^{\frac{\kappa+1}{2(\kappa-1)}} & ; \frac{p_{a}}{p}<\left(\frac{2}{\kappa+1}\right)^{\frac{\kappa}{\kappa-1}}\end{cases}
\end{aligned}
$$

where $C_{d}=$ discharge coefficient [-], $r=$ specific gas constant $[\mathrm{J} / \mathrm{kgK}], n_{e}, d_{e}=$ number per cylinder [-] and diameter [m] of the exhaust valves. The lift height $h_{e}^{\prime}[\mathrm{m}]$ is approximated by $h_{e}^{\prime}(\theta)=h_{e} \frac{1}{2}\left(1-\cos \left(2 \pi\left(\theta-\theta_{e}\right) / \Delta \theta\right)\right)$, where $h_{e}=$ maximum lift height, $\theta_{e}=$ start of exhaust valve opening [rad] and $\Delta \theta=$ exhaust valve opening duration [rad]. The expression for $h_{e}(\theta)$ 
is further approximated using a Taylor expansion for small values of $\left(\theta-\theta_{e}\right) / \Delta \theta$, and substituting $\omega t=\theta-\theta_{e}$ results in $h_{e}^{\prime}(\theta)=h_{e}(\pi / \Delta \theta)^{2} \omega^{2} t^{2}$, where $2 \pi \omega / 60=$ engine speed [rpm]. Note that $p$ and $T$ represent total conditions.

Substituting Eq. (15) in Eq. (16) and incorporating the above approximation for $h_{e}{ }^{\prime}$ results in:

$$
\frac{\partial}{\partial t}\left(\frac{m}{m_{e}}\right)=-C_{d} \frac{n_{e} \pi^{3} d_{e} h_{e}}{\Delta \theta^{2}} \omega^{2} t^{2} \frac{\sqrt{r T_{e}}}{V_{e}}\left(\frac{m}{m_{e}}\right)^{(\kappa+1) / 2} f\left(\frac{p_{a}}{p_{e}}\left(\frac{m}{m_{e}}\right)^{-\kappa}\right)
$$

For this partial differential equation to be solvable, the function $f$ is approximated using the following expression:

$$
f \cong f^{\prime}=c_{f}\left(\frac{m}{m_{e}}\left(\frac{p_{e}}{p_{a}}\right)^{1 / \kappa}\right)^{-(\kappa+1) / 2}\left(\frac{p_{e}}{p_{a}}\right)^{\frac{\kappa-3}{2 \kappa}}\left(\frac{m}{m_{e}}\left(\frac{p_{e}}{p_{a}}\right)^{1 / \kappa}-1\right)
$$

where $c_{f}=$ fit constant $[-]$.

Substituting Eq. (18) in Eq. (17) yields a solvable partial differential equation that describes the approximate evolution of $m$, the gas remaining in the cylinder:

$$
\begin{aligned}
\frac{\partial}{\partial t}\left(\frac{m}{m_{e}}\right) & =-C_{d} \frac{n_{e} \pi^{3} d_{e} h_{e}}{\Delta \theta^{2}} \omega^{2} t^{2} \frac{\sqrt{r T_{e}}}{V_{e}} c_{f}\left(\frac{p_{e}}{p_{a}}\right)^{-2 / \kappa}\left(\frac{m}{m_{e}}\left(\frac{p_{e}}{p_{a}}\right)^{1 / \kappa}-1\right) \\
& =-K t^{2}\left(\frac{1}{A} \frac{m}{m_{e}}-1\right)
\end{aligned}
$$

The solution to this partial differential equation is:

$$
\frac{m}{m_{e}}(t)=A+(1-A) \exp \left(-\frac{K}{3 A} t^{3}\right)
$$

where $K=C_{d} \frac{n_{e} \pi^{3} d_{e} h_{e}}{\Delta \theta^{2}} \omega^{2} t^{2} \frac{\sqrt{r T_{e}}}{V_{e}} c_{f}\left(\frac{p_{e}}{p_{a}}\right)^{-2 / \kappa} \quad\left[\mathrm{s}^{-3}\right]$ and $A=\left(\frac{p_{a}}{p_{e}}\right)^{1 / \kappa} \quad$ [-]. The flow rate yields:

$$
M(t)=-\frac{\partial m}{\partial t}(t)=m_{e} K(1 / A-1) t^{2} \exp \left(-\frac{K}{3 A} t^{3}\right)
$$

The maximum mass flow rate during blowdown $M_{1}[\mathrm{~kg} / \mathrm{s}]$ occurs at $t_{\max }=(2 \mathrm{~A} / \mathrm{K})^{1 / 3}[\mathrm{~s}]$ and equals $M_{1}=\max (M)=m_{e}\left(\frac{2}{e}\right)^{\frac{2}{3}}(K / A)^{\frac{1}{3}}(1-A)$.

Figure 19 (left) shows the approximation of $f$ in order to make Eq. (17) solvable. Figure 19 (right) shows the good correspondence between the analytically predicted mass flow rate 
according to Eq. (21) and the experimentally determined flow rate in an exhaust runner on the CME flow rig.
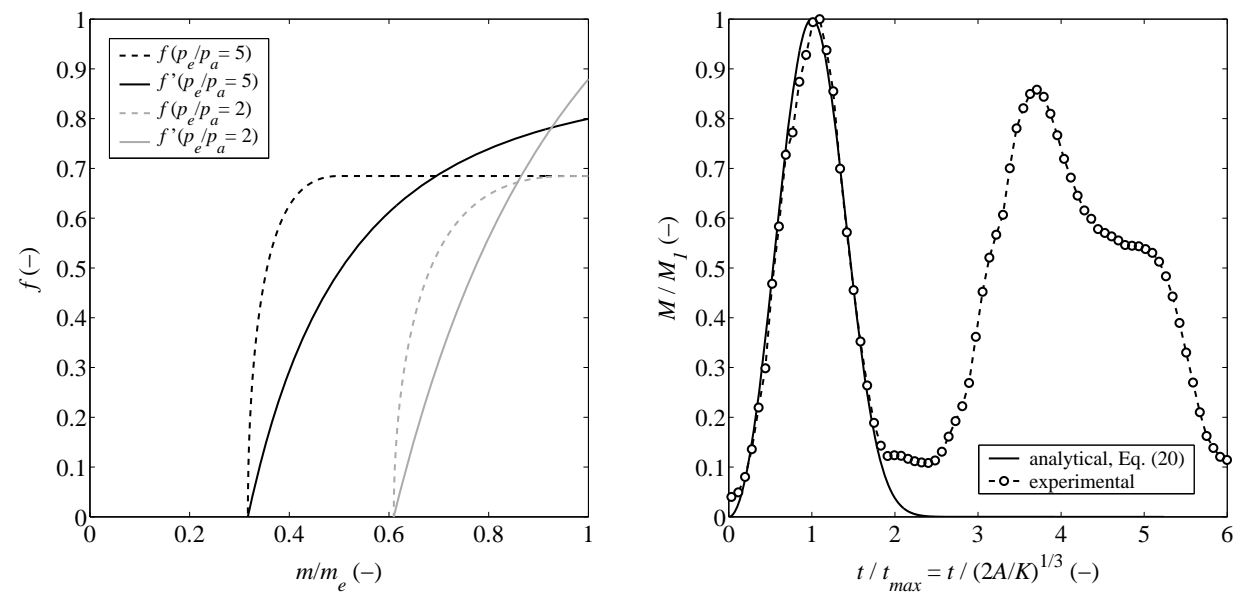

Figure 19. Approximation of $f$ according to Eq. (18) (left) and flow rate predicted by Eq. (21) compared to measured runner flow rate (right)

Substituting Eq. (14) and choosing the fit constant in Eq. (18) $c_{f}=2\left(\frac{2}{e}\right)^{-2} \cong 3.695$ yields:

$$
\begin{aligned}
M_{1}=\rho_{i} V_{i} \omega\left(2 C_{d} \frac{n_{e} \pi^{3} d_{e} h_{e}}{\Delta \theta^{2}} \frac{\sqrt{r T_{i}}}{\omega V_{i}}\right)^{\frac{1}{3}}\left(\frac{V_{i}}{V_{e}}\right)^{\frac{\kappa-7}{6}} \underbrace{\left(1+\frac{\Delta T_{c}}{T_{i}}\left(\frac{V_{0}}{V_{i}}\right)^{\kappa-1}\right)^{\frac{\kappa-8}{6 \kappa}}}_{i i} \\
\cdot \underbrace{\left(\frac{p_{i}}{p_{a}}\right)^{\frac{-4}{3 \kappa}}}_{i}(\underbrace{\left(\frac{p_{i}}{p_{a}}\right)^{\frac{1}{\kappa}}}_{i}\left(\frac{V_{i}}{V_{e}}\right) \underbrace{\left(1+\frac{\Delta T_{c}}{T_{i}}\left(\frac{V_{0}}{V_{i}}\right)^{\kappa-1}\right)^{\frac{1}{\kappa}}}_{i i}-1)
\end{aligned}
$$

During the displacement phase, cylinder pressure and density are assumed constant. From the conservation of mass results the following expression for the peak mass flow rate $M_{2}[\mathrm{~kg} / \mathrm{s}]$ during displacement:

$$
M_{2}=\rho_{i}\left(\frac{\pi b^{2}}{4} s\right) \frac{\omega}{2} \underbrace{\left.\frac{p_{i}}{p_{a}}\right)^{\frac{-1}{\kappa}}}_{i} \underbrace{\left(1+\frac{\Delta T_{c}}{T_{i}}\left(\frac{V_{0}}{V_{i}}\right)^{\kappa-1}\right)^{\frac{-1}{\kappa}}}_{i i}
$$

where $b$ and $s=$ cylinder bore and piston stroke $[\mathrm{m}]$.

\section{References}

1 Persoons, T., Van den Bulck, E. and Fausto, S. Study of pulsating flow in close-coupled catalyst manifolds using phase-locked hot-wire anemometry. Experiments in Fluids, 2004, 36(2), 217-232, DOI: 10.1007/s00348-003-0683-0. 
2 Persoons, T., Hoefnagels, A. and Van den Bulck, E. Experimental validation of the addition principle for pulsating flow in close-coupled catalyst manifolds. Journal of Fluids Engineering - Transactions of the ASME, (in press).

3 Benjamin, S. F., Roberts, C. A. and Wollin, J. A study of pulsating flow in automotive catalyst systems. Experiments in Fluids, 2002, 33(5), 217-232, DOI: 10.1007/s00348-0020481-0.

4 Arias-Garcia A., Benjamin S. F., Zhao H. and Farr, S. A comparison of steady, pulsating flow measurements and CFD simulations in close-coupled catalysts. SAE Paper 2001-01-3662, 2001.

5 Liu, Z., Benjamin, S. F. and Roberts, C. A. Pulsating flow maldistribution within an axisymmetric catalytic converter: Flow rig experiment and transient CFD simulation. SAE Paper 2003-01-3070, 2003.

6 Bressler, H., Rammoser, D., Neumaier, H. and Terres, F. Experimental and predictive investigation of a close-coupled catalyst converter with pulsating flow. SAE Paper 960564, 1996.

7 Hwang, K., Lee, K., Mueller, J., Stuecken, T., Schock, H. J. and Lee, J. C. T. Dynamic flow study in a catalytic converter using LDV and high speed flow visualisation. SAE Paper 950786, 1995.

8 Adam, M., Heinrich, M., Hopp, M. and Lang, O. Optimierung von Abgasanlagen mit analytischen Methoden. Motortechnische Zeitschrift, 2002, 63(10), 838-846.

9 Liu, Z., Benjamin, S. F., Roberts, C. A., Zhao, H. and Arias-Garcia, A. A coupled 1D/3D simulation for the flow behaviour inside a close-coupled catalytic converter. SAE Paper 2003-01-1875, 2003.

10 Park, S. B., Kim, H. S., Cho, K. M. and Kim, W. T. An experimental and computational study of flow characteristics in exhaust manifold and CCC (close-coupled catalyst). SAE Paper 980128, 1998.

11 Benjamin, S. F., Disdale, W., Liu, Z., Roberts, C. A. and Zhao, H. Velocity predictions from a coupled 1D/3D CFD simulation compared with measurements in the catalyst system of a firing engine. International Journal of Engine Research, (in press).

12 Kim, H. S., Min, K., Myung, C. L. and Park, S. A combined experimental and computational approach to improve catalyst flow uniformity and light-off behaviour. Proc. Instn. Mech. Engrs., Part D, Journal of Automobile Engineering, 2002, 216(5), 413-430.

13 Bruun, H. H. Hot-wire anemometry: Principles and signal analysis. Oxford University Press, Oxford (UK), 1995, Chap. 8.

14 Thompson, B. E. and Whitelaw, J. H. Flying hot-wire anemometry. Experiments in Fluids, 1984, 2(1), 47-55. 
15 Persoons, T., Hoefnagels, A. and Van den Bulck, E. Calibration of an oscillating hotwire anemometer for bidirectional velocity measurements. Experiments in Fluids, 2006, 40(4), 555-567, DOI: 10.1007/s00348-005-0095-4.

16 Weltens, H., Bressler, H., Terres, F., Neumaier, H. and Rammoser, D. Optimisation of catalytic converter gas flow distribution by CFD prediction. SAE Paper 930780, 1993.

17 Watson, N. and Janota, M. S. Turbocharging the internal combustion engine. The MacMillan Press Ltd., London (UK), 1982, Chap. 15.

18 Vandevoorde, M., Vierendeels, J., Sierens, R. and Dick, E. A new total variation diminishing scheme for the calculation of one-dimensional flow in inlet and exhaust pipes of internal combustion engines. Proc. Instn. Mech. Engrs., Part D, Journal of Automobile Engineering, 1998, 212(5), 437-448.

\section{List of tables}

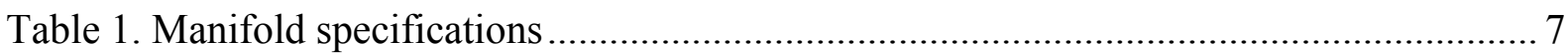

Table 2. Catalyst mean velocity peak fluctuation frequencies............................................. 19

\section{List of figures}

Figure 1. CME flow rig (left) and exhaust manifold (right) ................................................ 7

Figure 2. Comparison of exhaust runner velocity for CME and isothermal flow rig [1]......... 9

Figure 3. Mass flow rate versus engine load $p_{i} / p_{a}$, for (left) fired engine and (right) CME .... 11

Figure 4. Reynolds number versus engine load $p_{i} / p_{a}$, for (left) fired engine and (right) CME 11

Figure 5. Mach number versus engine load $p_{i} / p_{a}$, for (left) fired engine and (right) CME...... 11

Figure 6. Hot-wire oscillator ( $\mathrm{OHW}$ ) used to measure bidirectional velocity ......................... 12

Figure 7. OHW probe velocity, phase-locked with engine crankshaft position ...................... 13

Figure 8. Non-dimensional OHW calibration chart at varying oscillation frequency ............. 14

Figure 9. Influence of OHW frequency $R_{f}$ on flow rate deviation (left) and time-resolved

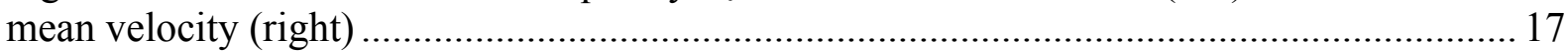

Figure 10. Time-resolved velocity on CME (left) and isothermal flow rig [1] (right), for comparable engine speed and flow rate $\left(\cong 100 \mathrm{~m}^{3} / \mathrm{h}\right)$

Figure 11. Time-resolved velocity in part (left) and zero (right) load conditions on CME flow

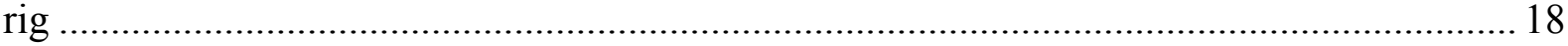

Figure 12. Spectra of time-resolved mean velocity during individual exhaust strokes on CME

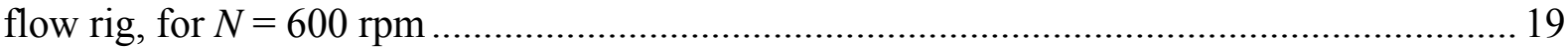

Figure 13. Lumped model of Helmholtz resonance in CCC exhaust manifold ...................... 20

Figure 14. Frequency response functions from cylinder pressure to catalyst velocity for exhaust manifold under investigation (left) and manifold A [1] (right) ............................... 21 
Figure 15. Time-averaged catalyst velocity (top) and time-resolved mean catalyst velocity and flow uniformity (bottom) for $1200 \mathrm{rpm}$ at zero (left), part (middle) and full (right) load ....... 24

Figure 16. Stationary catalyst velocity for steady flow through runner $\# 1$ at flow rates corresponding to zero (left), part (middle) and full (right) load in Fig. 15

Figure 17. Time-resolved catalyst velocity for $1200 \mathrm{rpm}$ at zero, part and full load (top to bottom), at crankshaft positions a, b, c (left to right)

Figure 18. Time-resolved catalyst velocity for $1200 \mathrm{rpm}$ at zero, part and full load (top to bottom), at crankshaft positions $\mathrm{d}, \mathrm{e}, \mathrm{f}$ (left to right)

Figure 19. Approximation of $f$ according to Eq. (18) (left) and flow rate predicted by Eq. (21) compared to measured runner flow rate (right). 